\title{
The ALOMAR Rayleigh/Mie/Raman lidar: objectives, configuration, and performance
}

\author{
U. von Zahn ${ }^{1}$, G. von Cossart ${ }^{1}$, J. Fiedler ${ }^{1}$, K. H. Fricke ${ }^{2}$, G. Nelke ${ }^{2}$, \\ G. Baumgarten ${ }^{2}$, D. Rees ${ }^{3}$, A. Hauchecorne ${ }^{4}$, K. Adolfsen ${ }^{5}$ \\ ${ }^{1}$ Leibniz-Institut für Atmosphärenphysik, Schloss-Str. 6, 18225 Kühlungsborn, Germany \\ ${ }^{2}$ Physikalisches Institut, Universität Bonn, Nussallee 12, 53115 Bonn, Germany \\ ${ }^{3}$ Hovemere Ltd., 56, Hayes St., Hayes, Bromley Kent, UK \\ ${ }^{4}$ Service d'Aéronomie du C.N.R.S., B.P. No. 3, 91370 Verrières le Buisson, France \\ ${ }^{5}$ Andøya Rocket Range, P.O. Box 54, 8480 Andenes, Norway
}

Received: 13 September 1999 / Revised: 31 January 2000 / Accepted: 25 February 2000

\begin{abstract}
We report on the development and current capabilities of the ALOMAR Rayleigh/Mie/Raman lidar. This instrument is one of the core instruments of the international ALOMAR facility, located near Andenes in Norway at $69^{\circ} \mathrm{N}$ and $16^{\circ} \mathrm{E}$. The major task of the instrument is to perform advanced studies of the Arctic middle atmosphere over altitudes between about 15 to $90 \mathrm{~km}$ on a climatological basis. These studies address questions about the thermal structure of the Arctic middle atmosphere, the dynamical processes acting therein, and of aerosols in the form of stratospheric background aerosol, polar stratospheric clouds, noctilucent clouds, and injected aerosols of volcanic or anthropogenic origin. Furthermore, the lidar is meant to work together with other remote sensing instruments, both ground- and satellite-based, and with balloon- and rocket-borne instruments performing in situ observations. The instrument is basically a twin lidar, using two independent power lasers and two tiltable receiving telescopes. The power lasers are Nd:YAG lasers emitting at wavelengths 1064,532 , and $355 \mathrm{~nm}$ and producing 30 pulses per second each. The power lasers are highly stabilized in both their wavelengths and the directions of their laser beams. The laser beams are emitted into the atmosphere fully coaxial with the lineof-sight of the receiving telescopes. The latter use primary mirrors of $1.8 \mathrm{~m}$ diameter and are tiltable within $30^{\circ}$ off zenith. Their fields-of-view have $180 \mu \mathrm{rad}$ angular diameter. Spectral separation, filtering, and detection of the received photons are made on an optical bench which carries, among a multitude of other optical components, three double Fabry-Perot interferometers (two for 532 and one for $355 \mathrm{~nm}$ ) and one single FabryPerot interferometer (for $1064 \mathrm{~nm}$ ). A number of separate detector channels also allow registration of photons which are produced by rotational-vibrational and rotational Raman scatter on $\mathrm{N}_{2}$ and $\mathrm{N}_{2}+\mathrm{O}_{2}$ molecules, respectively. Currently, up to 36 detector
\end{abstract}

Correspondence to: $\mathrm{U}$. von Zahn channels simultaneously record the photons collected by the telescopes. The internal and external instrument operations are automated so that this very complex instrument can be operated by a single engineer. Currently the lidar is heavily used for measurements of temperature profiles, of cloud particle properties such as their altitude, particle densities and size distributions, and of stratospheric winds. Due to its very effective spectral and spatial filtering, the lidar has unique capabilities to work in full sunlight. Under these conditions it can measure temperatures up to $65 \mathrm{~km}$ altitude and determine particle size distributions of overhead noctilucent clouds. Due to its very high mechanical and optical stability, it can also employed efficiently under marginal weather conditions when data on the middle atmosphere can be collected only through small breaks in the tropospheric cloud layers.

Key words: Atmospheric composition and structure (aerosols and particles; pressure, density, and temperature; instruments and techniques)

\section{Introduction}

The Arctic middle atmosphere is still much less explored than most other regions of the Earth's atmosphere. Much of what we know points to a dramatic variability of its thermal, dynamic, and even chemical state. The exploration of the middle atmosphere is particularly difficult for the regions between 40 and $120 \mathrm{~km}$ altitude, which are inaccessible to aeroplanes and balloons and hard to study using either rockets or satellites. However, modern lidar technology has made it possible to measure from the ground numerous atmospheric parameters up to $120 \mathrm{~km}$, some of them with high spatial resolution and/or short integration times. Recognizing these new possibilities for active remote sensing of the middle atmosphere by ground-based instruments and 
the need to expand our understanding of the processes acting in the Arctic middle atmosphere, we decided to set up and operate a major state-of-the-art lidar at an Arctic location. Furthermore, because of its close location to the Andøya Rocket Range, it offers the capability of combining its high-quality remote sensing observations with simultaneous in-situ measurements by balloon- and rocket-borne instruments.

Studies for the configuration of an advanced lidar for Arctic atmosphere research, the search for potential sites for such an instrument as well as the formation of an international instrument team started in 1990. First funding proposals were submitted in 1991. The site of the ALOMAR observatory for which the RMR lidar is the core instrument was selected in September 1991. Initial funding for instrument development was received in February 1992. On January 31, 1992, the first of a long series of regular meetings of the RMR lidar team took place at Bonn University, Germany. During April/ May 1994 major parts of the lidar were moved into the newly constructed ALOMAR observatory. On June 19, 1994, the first atmospheric profile was taken and six weeks later the first overhead noctilucent cloud was measured. Since January 1, 1995, the RMR lidar has been in near-continuous use for climatological observations of the Arctic atmosphere. Since that time, the instrument has been significantly upgraded which means that during the past five years it has gone through a variety of configurations. This report will concentrate on reporting the current configuration and capabilities of the lidar. As regards scientific results obtained using the RMR lidar, we append a list of references to selected papers.

The RMR lidar is a joint effort between four European partners: the Leibniz-Institute of Atmospheric Physics (Kühlungsborn, Germany), the Institute of Physics of Bonn University (Bonn, Germany), the Service d'Aéronomie du C.N.R.S. (Verrières le Buisson, France) and Hovemere Ltd. (Keston, UK). The RMR lidar is located in the ALOMAR observatory, which embodies many special features for this instrument and which is an entirely Norwegian effort led by the Andøya Rocket Range (Andenes, Norway).

\section{Design objectives for the RMR lidar}

The RMR lidar was designed to provide measurement capabilities for a variety of tasks and parameters, some of which are at the edge of present-day lidar technology. Table 1 gives a concise survey of these tasks, on which we will comment as follows.

\subsection{Capability for daylight observations}

The development of extensive daylight measurement capabilities of the RMR lidar was introduced basically for two reasons: (1) the ALOMAR observatory is located $2^{\circ}$ north of the Arctic circle and hence it experiences continuous sunlight from about mid-May until the end of July. This is a geophysically very interesting period because of the presence of noctilucent clouds (NLC) and of polar mesosphere summer echoes (PMSE). Summertime observations are also important for climate trend studies. As pointed out by Hauchecorne et al. (1991), the reduced variability of atmospheric parameters in summer, related to a minimum of planetary wave activity, facilitates the detection of trends. However, lidar observations during this period need to perform these observations in bright sunlight. (2) There is great interest in tidal phenomena. To quantify diurnal tides in density, temperature, wind, and NLC particle properties, the lidar must be able to perform its measurements at night and day with the sun up to $43^{\circ}$ above the horizon.

The capability for daylight observations was realized by a combination of strong spatial and spectral filtering of the photons collected by the telescopes. For spatial filtering a rather small field-of-view (FOV) of the receiving telescopes $(180 \mu \mathrm{rad})$ is used. This choice in turn made it necessary to work with a very small divergence of the laser beams $(<100 \mu \mathrm{rad})$ and to actively stabilize and control the direction of the laser beam $( \pm 20 \mu \mathrm{rad})$. Spectral filtering is applied at a bandpass of a few pm, which is sufficiently wide to include the entire Doppler widened backscatter signal of a few picometer FWHM, and at the same time sufficiently narrow to exclude most of the scattered solar photons. To this end, double etalon Fabry-Perot (FP) interferometers were marked out for detection of the signals at $532 \mathrm{~nm}$ and $355 \mathrm{~nm}$ and a single etalon FP interferometer for $1064 \mathrm{~nm}$ (plus narrow bandwidth interference filters).

Another challenge for lidar operations in daylight is the start-up procedure which requires guidance of the laser beams into the minute FOV of the telescopes under sunlit conditions. One prerequisite for meeting this challenge is to provide a mechanically ultra-stable design for the transmitters and receiving telescopes of the instrument.

\subsection{Capability for multi-wavelength measurements}

For temperature profiling in atmospheric regions which do not contain aerosols or cloud particles, the RMR lidar measures the Rayleigh backscatter on air molecules, or more precisely the Cabannes line in the green (at $532 \mathrm{~nm}$ ) and the UV (at $355 \mathrm{~nm}$ ) bands for the determination of hydrostatic temperature from air density. Use of two independent spectral channels furnishes checks on the internal consistency of the deduced temperature profiles.

For temperature profiling in atmospheric regions which contain aerosols or polar stratospheric clouds, the RMR lidar measures the rotational-vibrational Raman scatter on $\mathrm{N}_{2}$ molecules in the green $(608 \mathrm{~nm})$ and the UV $(387 \mathrm{~nm})$ for the determination of hydrostatic temperature from air density and in two bands of the $\mathrm{N}_{2}+\mathrm{O}_{2}$ rotational Raman spectra (530.4 and $529.1 \mathrm{~nm}$ ) for the direct determination of the temperature from the 
Table 1. Special capabilities of the instrument

\begin{tabular}{|c|c|c|c|}
\hline Daylight observations & $\begin{array}{l}\text { Shape and size distribution } \\
\text { of particles }\end{array}$ & Wind measurements & Process studies \\
\hline $\begin{array}{l}\text { Very small telescope } \\
\text { field-of-view }(180 \mu \mathrm{rad})\end{array}$ & Depolarization measurements & $\begin{array}{l}\text { Two Nd:YAG power } \\
\text { lasers with } \\
\text { - bandwidth }<70 \mathrm{MHz}\end{array}$ & $\begin{array}{l}\text { Simultaneous multi-parameter } \\
\text { observations in a common } \\
\text { volume }\end{array}$ \\
\hline $\begin{array}{l}\text { Coaxial configuration of } \\
\text { transmitter and receiver }\end{array}$ & $\begin{array}{l}\text { Simultaneous multi-colour } \\
\text { soundings }\end{array}$ & $\begin{array}{l}\text { - output frequency } \\
\text { stabilized against } \mathrm{I}_{2} \text { line }\end{array}$ & $\begin{array}{l}\text { High dynamic range } \\
\text { (up to } 3 \text { PMT's per wavelength) }\end{array}$ \\
\hline $\begin{array}{l}\text { Very small laser beam } \\
\text { divergence: }<100 \mu \mathrm{rad} \\
\text { after beam widening }\end{array}$ & $\begin{array}{l}\text { Five detected wavelengths: } \\
1064 \mathrm{~nm} \\
608 \mathrm{~nm} \\
532 \mathrm{~nm} \\
387 \mathrm{~nm} \\
355 \mathrm{~nm}\end{array}$ & $\begin{array}{l}\text { Double etalon FP inter- } \\
\text { ferometer coupled to a } \\
\text { 24-ring-anode imaging } \\
\text { photon detector } \\
\text { (0.3 pm FWHM bandwidth) }\end{array}$ & $\begin{array}{l}\text { Multi-colour detection } \\
\text { ( } 9 \text { wavelengths), including: }\end{array}$ \\
\hline $\begin{array}{l}\text { Spectral filtering by FP } \\
\text { interferometers with } \\
<10 \text { pm FWHM } \\
\text { bandwidth (for } 3 \text { colours) }\end{array}$ & & & $\begin{array}{l}\text { Rotational Raman channels: } \\
530.4 \mathrm{~nm} \\
529.1 \mathrm{~nm}\end{array}$ \\
\hline
\end{tabular}

ratio of the signals in the two bands. The latter gives the RMR lidar a unique capability for measuring temperatures inside polar stratospheric clouds, independent of the cloud optical thickness.

For the determination of the size distributions of aerosol and cloud particles one needs to measure the Mie backscatter signal on at least three appropriately spaced wavelengths. These and the other stated objectives can be met with Nd:YAG lasers, including devices for doubling and tripling of the laser frequencies. The resulting wavelengths are $1064 \mathrm{~nm}, 532 \mathrm{~nm}$, and $355 \mathrm{~nm}$.

It is this simultaneous use of Rayleigh, Mie, and Raman scatter for studying the structure and particles of the middle atmosphere which led to the name "Rayleigh/Mie/Raman lidar" for our instrument.

\subsection{Capability for Doppler wind measurements}

Very few wind measurements were available for the altitude region from 30 to $70 \mathrm{~km}$ altitude. The incoherent Doppler wind lidar method was devised to be able to close that gap. More specifically, to make Doppler wind measurements possible, the RMR lidar employs two power lasers with the same and highly stabilized wavelengths, two tiltable telescopes, an imaging FP interferometer and 24-channel photon detector to achieve the required combination of very high spectral stability, spectral resolution, and sensitivity. At the wavelength of $532 \mathrm{~nm}$, a wind velocity of $1 \mathrm{~m} / \mathrm{s}$ along the line-of-sight (LOS) will cause a shift of $2 \times 1.8 \mathrm{fm}=$ $3.6 \mathrm{fm}$, corresponding to an absolute frequency shift of $3.8 \mathrm{MHz}$ and relative frequency shift of $7 \times 10^{-9}$.
The ALOMAR Doppler wind experiment benefits greatly from the availability of two inclined beams, and it is mainly to meet the objectives of Doppler wind measurements that led us to develop the RMR lidar as a two-laser/two-telescope system. We should also note that by measuring the mean-square Doppler velocity as a function of range, it is possible to measure the vertical profile of horizontally directed momentum flux (Vincent and Reid, 1983), a capability of which we intend to take advantage in the future.

\subsection{Capabilities for "marginal weather" observations}

In order to increase its opportunities for observations, the RMR lidar should be capable of performing observations also under conditions of broken clouds and/or thin cirrus layers. Both scenarios frequently apply at the polar latitude site of ALOMAR.

\subsection{High reliability and a large degree of automation of the instrument operations}

The goal of building into the RMR lidar (a) high reliability and (b) a large degree of automation is driven by the necessity to minimize the manpower and expenditures required to operate and maintain the instrument at a polar latitude location. Today, these aims have been achieved as will be demonstrated by a number of examples. A complete automation and remote control of the entire instrument has not been a design objective for the RMR lidar, in part because of 
the difficulty to react automatically and properly to all local weather changes.

\section{Instrument description}

The RMR lidar started operating during the summer of 1994, though in a minimum configuration which included only one small receiving telescope and limited capabilities for daylight observations at one wavelength. Over the past five years, the instrument has been much upgraded and now approaches its originally planned configuration, and we now describe the present (summer 1999) configuration and current instrument capabilities.

Figure 1 provides a schematic of the major instrument subassemblies. A single cw laser is used to seed the two power lasers (lasers I and II). Their laser beams are passed through the beam widening telescopes (BWTs) to the telescopes. Two tiltable telescopes are used to collect photons backscattered from the atmosphere. The photons are transferred via fibre cables to a single detection system.

\subsection{Layout of the lidar in the ALOMAR observatory}

For the reader, it is useful to point out at the very beginning that what we describe here is a major lidar the top of the receiving telescopes from where they are emitted into the atmosphere coaxially with the LOS of

instrument, too bulky to be placed in a standard physics laboratory or container. The RMR lidar is installed in an observatory building, the ALOMAR observatory, which was designed and built for the purpose of housing complex lidars. At its centre is a $7 \times 7 \times 7 \mathrm{~m}$ large hall for the receiving telescopes (von Zahn et al., 1995). The telescope hall is surrounded by a octagonal two-story building. On its ground floor, the RMR lidar occupies one laboratory room for the twin laser assembly, one laboratory for the electronics and power supplies required for operation and control of its two receiving telescopes, and one office room. On the first floor, the RMR lidar uses one large laboratory for its detection system and another room for the operator of the lidar and for a cluster of computers which drive and control the instrument. A picture of the ALOMAR observatory can be found on the frontispiece of the June 1, 1999 issue of Geophysical Research Letters.

\subsection{Lasers}

According to the design objectives for the RMR lidar (see Sect. 2), the transmitter system of the RMR lidar should have the following capabilities:

1. A very small laser beam divergence and active stabilization of the direction of the emitted laser beam;

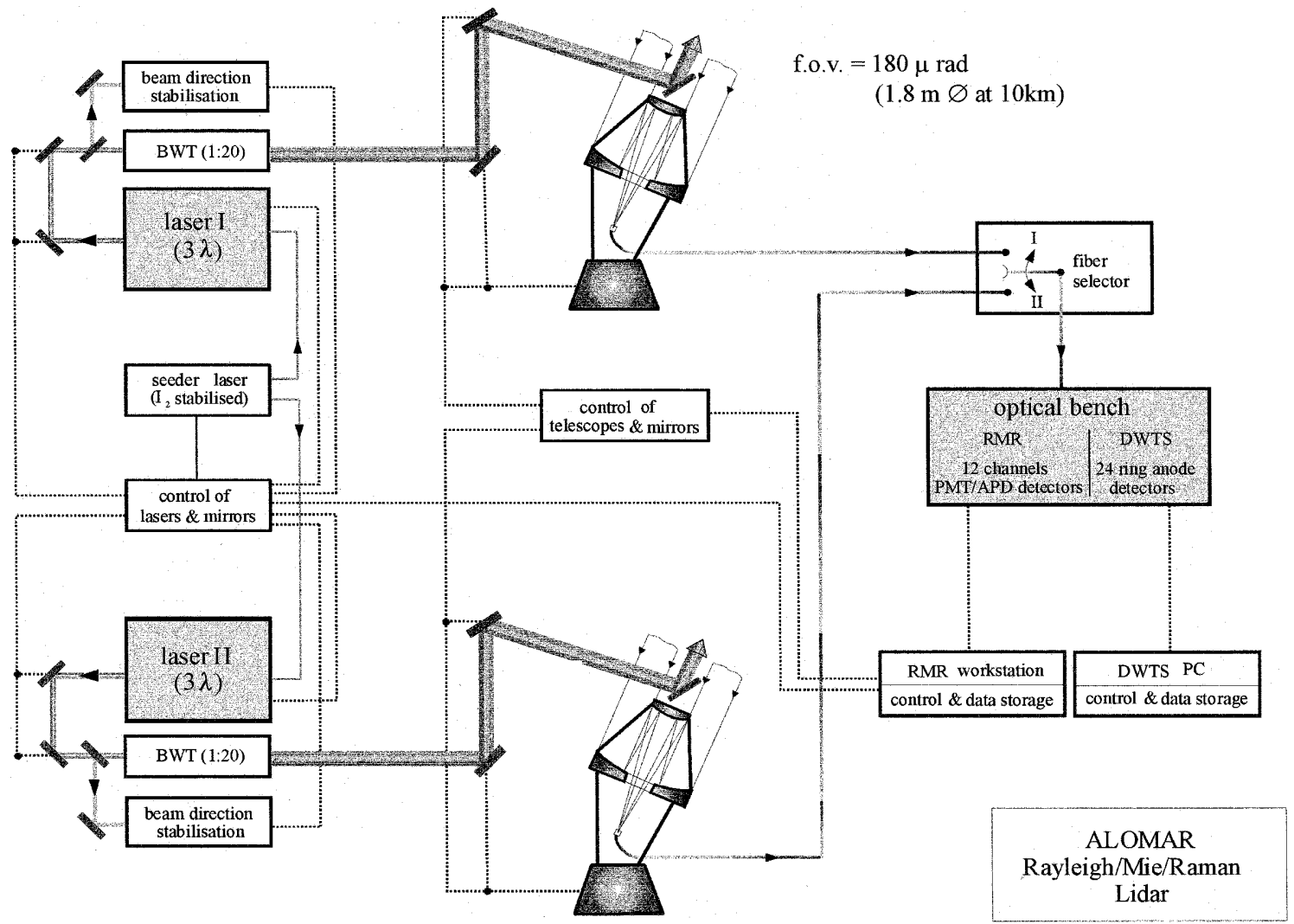

Fig. 1. A schematic of the major instrument subassemblies. A single cw laser is used to seed the two power lasers (lasers $I$ and II); their laser beams are passed through the beam widening telescopes $(B W T)$ to the top of the receiving telescopes from where they are emitted into the atmosphere coaxially with the line-of-sight of the telescopes. Two tiltable telescopes are used to collect photons backscattered from the atmosphere. The photons are transferred via fibre cables to a single detection system 
2. Simultaneous transmission of three coaxial beams with different wavelengths from the same laser;

3. Pulsed lasers with extraordinary frequency stability; and

4. Simple handling and thus a high degree of automation of the entire transmitter system.

The main components of the lidar transmitter are: the seeder system, two identical power laser systems, the synchronization electronics, and three control computers. All the equipment, except the voltage supplies for the power lasers, is located within one temperaturestabilized room. Each power laser system consists of an optical table, pulsed Nd:YAG laser Spectra Physics GCR-6-30, two piezo-controlled mirrors (BGM 1 and 2), equipment for guiding and controlling the laser beam, and a beam widening telescope (Fig. 2).

From both GCR lasers we removed their built-in seeders and substituted them with one external seeder laser to produce single-mode, narrow-bandwidth pulses of the same wavelength from both power lasers. This seeder system consists of a single-mode cw Nd:YAG laser Lightwave Electronics LWE-140. We stabilize its wavelength with the help of an external iodine absorption cell. The fundamental emission of the power laser at $1064 \mathrm{~nm}$, the second harmonic at $532 \mathrm{~nm}$, and the third harmonic at $355 \mathrm{~nm}$ are used simultaneously. The laser pulses are triggered externally from a mechanical light chopper located at the detection system of the lidar.

The temperature of the cooling water to the laser heads needs to be tightly stabilized to better than $\pm 0.2{ }^{\circ} \mathrm{C}$. Reasons for this are (a) to match the wavelength of the power laser to the stabilized wavelength of the seeder and (b) to maintain a rather small, but constant divergence of the laser beams (determined by the thermal lensing effects inside the power lasers).

After leaving the lasers, each laser beam is guided by two piezo-controlled mirrors BGM 1 and 2 into its beam widening telescope. The directions at which the beams enter their beam widening telescopes are measured accurately by CCD cameras. By means of laser beam analysers Spiricon LBA-100A and a control computer, servo signals are generated and applied to the mirrors BGM 1 and 2 (see later) which actively stabilize the directions of the laser beams.

The synchronization electronics is responsible to ensure the correct timing of the mechanical chopper, firing of the power lasers, and triggering other equipment. Although there are two independent groups of power lasers and receiving telescopes, the lidar has only a single set of detector channels. Therefore using simultaneous operation of both power lasers, the lasers are triggered alternately on a pulse-by-pulse basis. The trigger pulses have to be synchronized with the operation of the mechanical chopper. The effective pulse repetition rate is $30.3 \mathrm{~Hz}$ for each of the two lasers (hence about 60 sets of atmospheric data are received per second). The chopper speed is close to 15000 revolutions per minute. Table 2 summarizes the parameters of the lidar transmitter. A performance figureof-merit for any lidar is its product of laser power and the nominal area of the receiving telescope(s). For our RMR lidar, this figure-of-merit is $2 \times 28.5 \mathrm{~W} \times$ $2.54 \mathrm{~m}^{2}=145 \mathrm{~W} \mathrm{~m}$. A more detailed description of the RMR lidar transmitters and their performance figures has been given by Fiedler and von Cossart (1999).

Three computers are used to control the entire transmitter equipment. A combination of DOS operating system and real-time multitasking kernel (RTKernel by On Time Informatik $\mathrm{GmbH}$ ) has been chosen. A laser computer acts as controller for both power lasers, the seeder system, and the synchronization electronics. A remote workplace of the laser computer allows the interaction with the transmitter side from the central control and operation room of the lidar. Turn-on of the

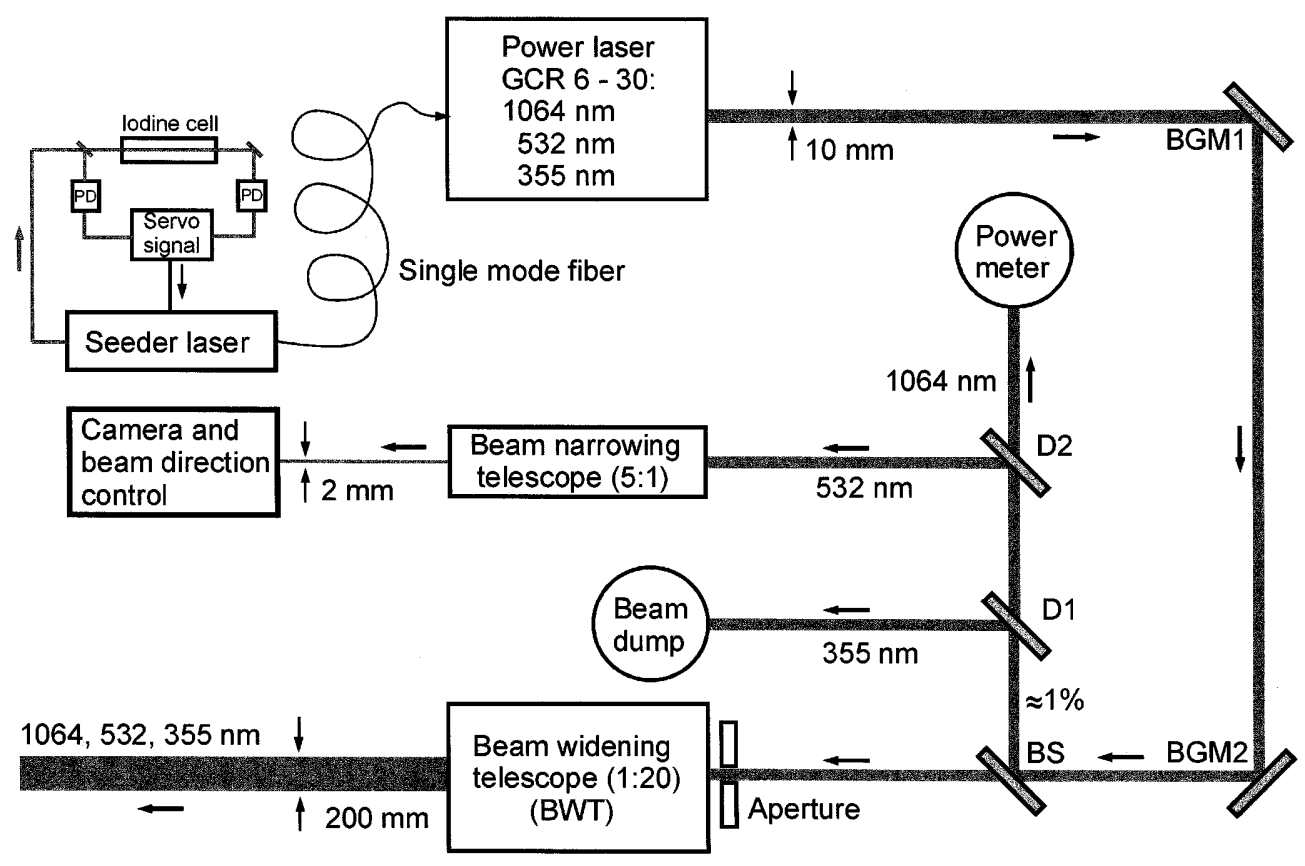

Fig. 2. Main components of the lidar transmitter: the seeder system, two identical power laser systems, the synchronization electronics, and three control computers. All the equipment, except the voltage supplies for the power lasers, is located within one temperature stabilized room. Each power laser system consists of an optical table, pulsed Nd:YAG laser, the two piezocontrolled mirrors BGM 1 and 2, equipment for guiding and controlling the laser beam laser, and a beam widening telescope 
Table 2. Parameters of the RMR lidar transmitter

\begin{tabular}{|c|c|c|c|}
\hline \multicolumn{4}{|l|}{ Seeder laser: } \\
\hline Type & $\begin{array}{l}\text { Single-mode cw Nd:YAG laser } \\
\text { (Lightwave Electronics LWE-140) }\end{array}$ & & \\
\hline Wavelengths & $1064 \mathrm{~nm}, 532 \mathrm{~nm}$ & & \\
\hline \multicolumn{4}{|l|}{ Power lasers ( 2 identical ones): } \\
\hline Type & $\begin{array}{l}\text { Injection seeded, pulsed Nd:YAG laser } \\
\text { (Spectra Physics GCR-6-30) }\end{array}$ & & \\
\hline Spectral width & $<70 \mathrm{MHz}$ at $532 \mathrm{~nm}$ & & \\
\hline Beam pointing stability & $< \pm 20 \mu \mathrm{rad}$ for each axis before beam widening & & \\
\hline Beam diameter & $200 \mathrm{~mm}$ after beam widening & & \\
\hline Beam full divergence & $<100 \mu \mathrm{rad}$ after beam widening & & \\
\hline Wavelength & $1064 \mathrm{~nm}$ & $532 \mathrm{~nm}$ & $355 \mathrm{~nm}$ \\
\hline Pulse power (for each laser) & $11 \mathrm{~W}$ & $11 \mathrm{~W}$ & $6.5 \mathrm{~W}$ \\
\hline
\end{tabular}

lasers is solely computer-controlled with no manual optical adjustment. The power lasers are brought into operation by stepwise raising of the flash lamp energy. During this procedure, the laser beams are captured by the beam direction stabilization systems. A few minutes after turn-on, the transmitters begin to work within the normal parameter ranges. A second computer, the mirror computer, is responsible for guiding both power laser beams into their beam-widening telescopes. A third computer acts as interface between lidar transmitter and the outside world, giving access to housekeeping data of the lasers through the Internet.

3.2.1 Stabilization of the laser frequency. Doppler wind measurements benefit greatly from a high spectral stability of the laser source. In addition, to have both power lasers operating at exactly the same frequency allows us to use in the detection system only a single set of high-resolution interferometers for both branches of our twin lidar. That is why we use a single external seeder to drive both power lasers and aim at reaching a wavelength stability of a few MHz. To this end, the Nd:YAG seeder laser is mounted onto a temperaturecontrolled base plate. The seeder laser generates both the fundamental and second harmonic at $1064 \mathrm{~nm}$ and $532 \mathrm{~nm}$, respectively. The wavelengths can be tuned by changing the laser crystal temperature as well as by applying an external control voltage to the laser head. The $1064 \mathrm{~nm}$ output is split and guided via single mode fibres into both power laser resonators.

To eliminate any long-term drift and to minimize the short-term drift, we set up an absolute frequency stabilization by locking the seeder harmonic to the half power point of an iodine absorption line. For more detailed information and references see Fiedler and von Cossart (1999). The iodine cell is operated at room temperature. We calibrated the change of seeder frequency versus the control voltage by means of a highresolution spectrum analyser with a free spectral range of $1 \mathrm{GHz}$ at $532 \mathrm{~nm}$. This yields in connection with a 16-bit digital/analog converter a control resolution of $290 \mathrm{kHz}$. A test run of $66 \mathrm{~h}$ length at constant temperature of $17.7^{\circ} \mathrm{C}$ showed residual frequency fluctuations of $\delta \mathrm{f}=0.84 \mathrm{MHz}$. From the change of control voltage we can derive that over this time period the seeder laser frequency would have drifted $52 \mathrm{MHz}$ (or the measured Doppler wind velocity by $14 \mathrm{~m} / \mathrm{s}$ ) if not externally stabilized.

3.2.2 Direction and divergence of the laser beams. In order to reduce the sky background during daylight observations, the receiving telescopes of the RMR lidar use FOVs of only $180 \mu \mathrm{rad}$ full angle. To keep the laser beams within these small FOVs, the directions of the laser beams are actively stabilized. The two GCR-6-30 power lasers emit beams with diameters of about $9 \mathrm{~mm}$. As shown in Fig. 2 for one of the lasers, the laser beam is guided over two beam guiding mirrors (BGM 1 and 2) through a beam forming aperture of $10 \mathrm{~mm}$ diameter into a beam widening telescope (BWT). The carriers of BGM 1 and 2 are constructed using hysteresis-free solidstate links with piezo drivers which allow an absolute angle accuracy of $1 \mu \mathrm{rad}$. Both BGM 1 and 2 and the entrance mirror inside the BWT are coated for the three wavelengths emitted by the power laser. In front of the BWT, the beam-splitter BS produces a low intensity reference beam which is passed through a beam narrowing telescope. The latter decreases the diameter of the reference beam by a factor of 5 to about $2 \mathrm{~mm}$ and increases its directional changes and the beam divergence by the same factor. After an additional path of $3 \mathrm{~m}$, a CCD camera connected to a laser beam analyser is used to monitor the position of the energy centroid of the reference beam.

Fluctuations of the power laser beam position consist of lateral as well as angular deviations. The contributions of both cause the overall deviation and were measured using two CCD cameras with different distances to the laser aperture. It has been found that lateral changes of the beam direction are limited to less 
than $40 \mu \mathrm{m}$, leading to an altitude-independent change of the beam diameter of less than $2 \mathrm{~mm}$ after beam widening. This amount is entirely negligible. Thus it is sufficient to use only one CCD camera and interpret all observed position fluctuations as angular deviations. The energy centroid position of single laser pulses at the CCD camera are measured up to 6 times per second. New positions for both mirrors and both axes, horizontal as well as vertical, are calculated and sent to the mirror controllers.

In the BWTs, the laser beams are widened by a factor of 20 before transmission into the atmosphere. The BWTs are off-axis collimators with a focal length of $2000 \mathrm{~mm}$, an axes separation of $160 \mathrm{~mm}$ and a useful diameter of the primary mirror of $235 \mathrm{~mm}$. Each of the BWT units has overall dimensions of $2040 \mathrm{~mm}$ length and $350 \mathrm{~mm}$ diameter.

The divergence of the laser beams when exiting the lasers is specified to be $500 \mu \mathrm{rad}$ (full angle). With a beam widening factor 20 one could expect a nominal divergence of $25 \mu \mathrm{rad}$ behind the BWTs. The effective divergence will be larger, however, due to deficiencies of the seven mirrors used for laser beam guidance, alignment errors (in particular in the BWTs), and diffraction effects. At the time of writing, we have not been able yet to measure the effective divergence of the laser beams in the far-field. We consider a figure of $100 \mu \mathrm{rad} \mathrm{a}$ conservative upper limit.

\subsection{Guidance of laser beams into the atmosphere}

In order to optimize the overlap of the FOVs of the telescopes with the laser beams, the beams are emitted into the atmosphere coaxially with the LOSs of the telescopes (Fig. 3). The laser beams enter the telescope hall horizontally with a diameter of $20 \mathrm{~cm}$ about $1.5 \mathrm{~m}$ above the floor. The BGMs 3 deflect them upward almost to the roof, where they hit BGMs 4 well above the telescope structure. The beams are guided slightly downward to the tops of the secondary mirror assemblies of the telescopes, where BGMs 5 align the laser beams with the telescope LOS. BGMs 4 can be used to couple each laser with either one of the telescopes, giving redundancy in case a telescope or a particular laser are not fully functional. Once aligned, the BGMs 5 are controlled by a servo loop which is driven by a CCDcamera near the focal plane and which will automatically maintain the alignment.

While tilting the telescopes (to a maximum of $30^{\circ}$ off zenith), their secondary mirrors change quite considerably their position in the telescope hall and their attitude. This requires BGM 4 and 5 to perform similarly large changes of their angular positions to maintain the laser beams in the telescopes FOV. These mirror positions have been experimentally calibrated and stored in the controlling computers for a large (and still increasing) number of viewing directions of the telescopes.

\subsection{Receiving telescopes}

The design of our receiving telescopes was driven by the following boundary conditions:

a. The two primary mirrors were made available to us by the European Southern Observatory on a loan

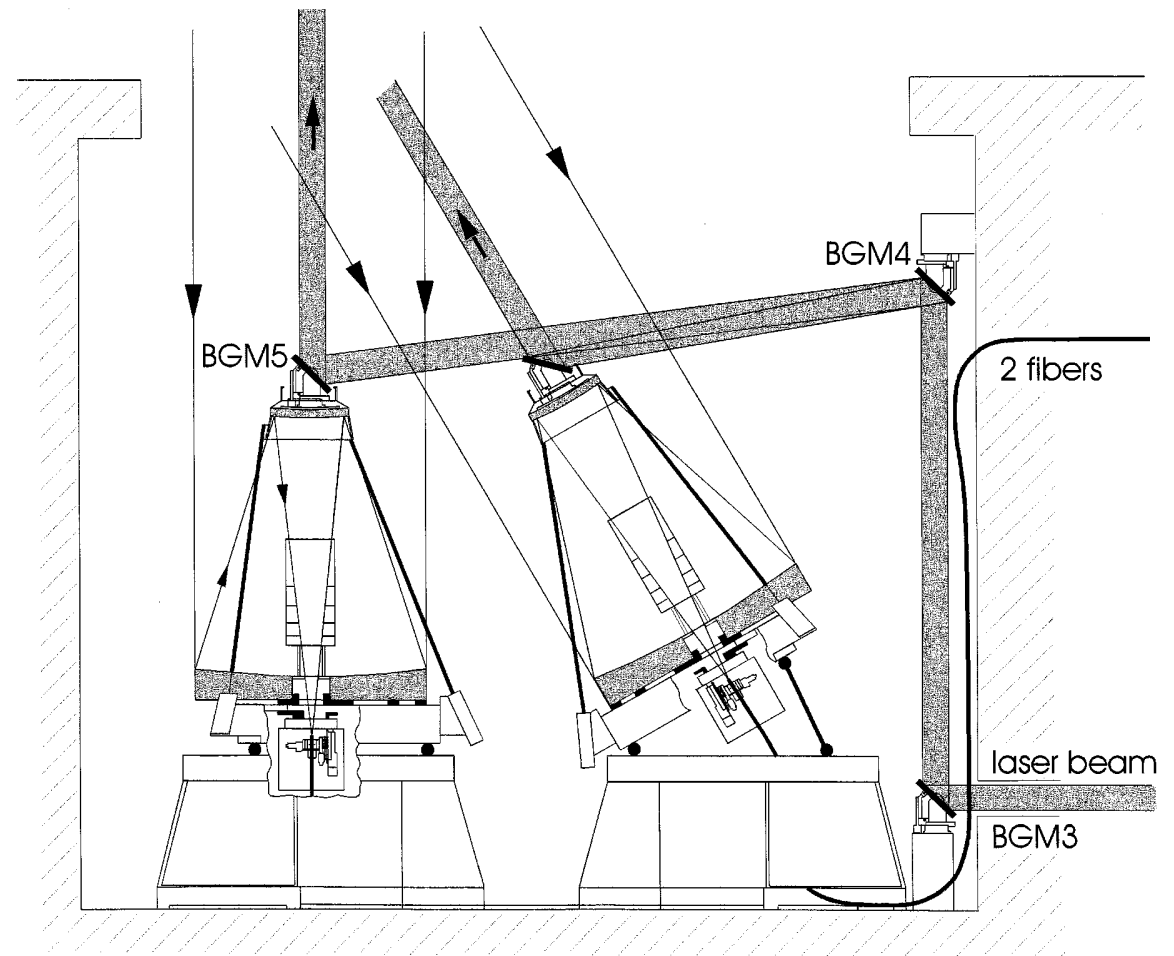

Fig. 3. Laser beam guidance and telescope schematic: The laser beams enter the telescope hall horizontally with a diameter of $20 \mathrm{~cm}$ about $1.5 \mathrm{~m}$ above the floor. The mirrors $B G M s 3$ deflect them upward until they hit BGMs 4 well above the telescope structure. The beams are guided slightly downward to the tops of the secondary mirror assemblies, where BGMs 5 align the laser beams with the telescope LOSs. Thus, the laser beams are emitted into the atmosphere coaxially with the LOSs of the telescopes. Once aligned, the $B G M 5$ is controlled by a servo loop which is driven by a CCD-camera near the focal plane 
basis. Their diameter is $1.8 \mathrm{~m}$, their shape quasispherical, their radius of curvature $5.98 \mathrm{~m}$, their focal length $2.99 \mathrm{~m}$, their material an aluminum alloy, and their weight $1.45 \mathrm{t}$ each.

b. We decided to limit the maximum tilt angle of the telescope axes to $30^{\circ}$ off zenith.

c. Mostly in order to save in size of the required telescope hall, we decided to limit the viewing directions of each telescope to one quadrant in the sky. Thus, the NW-telescope can be tilted into the quadrant between north and west, and similarly the SE-telescope between south and east. This arrangement obviously allows coverage of the vertical, the four cardinal directions and many positions in between. In particular, the NW-telescope can be tilted to all combinations of azimuth and elevation towards which any sounding rocket or meteorological rocket can be launched from the close-by Andøya Rocket Range.

3.4.1 Optical design. We have chosen a Cassegrain system as basic design for our telescopes (Fig. 3). For physical accessibility we chose to place the focal plane $0.5 \mathrm{~m}$ below the primary mirror vertex. The desired spectral resolution of the wind and daylight etalons and affordable etalon diameters ultimately defined a value for Abbe's sine invariant for the illuminating beam in the optical bench. This combination of focus location and sine invariant led to the following dimensions for the secondary mirror: focal length $-1.44 \mathrm{~m}$, radius of curvature $-2.87 \mathrm{~m}$, and diameter $0.58 \mathrm{~m}$ with a resulting weight of $30 \mathrm{~kg}$. Because the primary mirror is (almost) spherical, the secondary must be aspherical to eliminate spherical aberration. The resulting Cassegrain system focal length is $8.34 \mathrm{~m}$ with a mirror separation of $2.07 \mathrm{~m}$. The telescope numerical aperture NA is $\mathrm{D} / 2 \mathrm{f}=0.11$. Abbe's sine invariant and the primary mirror diameter determine the field of view of the telescope to be $180 \mu \mathrm{rad}$. Matching quartz/quartz fibres with $\mathrm{NA}=0.11 \pm 0.015$ and diameter $1.5 \mathrm{~mm}$ were obtained from Ceram Optics with transmission varying from 98\%/m@355 nm,99.6\%/m@532 nm to 99.7\%/ $\mathrm{m} @ 1064 \mathrm{~nm}$. The fibre cable diameter also fixes the (full) FOV of our telescopes to $1.5 / 8340=180 \mu \mathrm{rad}$.

The telescope optics in combination with the selected diameter of the fibre cable determine the depth of focus. Most commonly we place the front end of the fibre cable in such a position that the depth of focus reaches from about $12 \mathrm{~km}$ to $100 \mathrm{~km}$ distance.

3.4.2. Mechanical design. The lidar telescopes have to operate at ambient temperatures which vary between $+25^{\circ} \mathrm{C}$ and $-20{ }^{\circ} \mathrm{C}$. Furthermore, temperature changes of more than $10^{\circ} \mathrm{C}$ over half an hour can occur inside the telescope hall after opening of the roof. Therefore it was necessary to observe strictly the principles of forcefree mountings in the design of the opto-mechanical apparatus. This requires making the degrees of freedom exactly zero for all mountings. Taking the $1.8 \mathrm{~m}$ aluminum alloy mirror as a starting point, the whole tiltable tube construction including the primary mirror, the secondary mirror cell, and the secondary mirror itself were made from aluminum alloys. This has two major advantages: (a) because the heat conductivity of aluminum is large and its heat capacity relatively small, the opto-mechanical telescope structure follows these changes in less than one hour even when temperature changes of more than $10{ }^{\circ} \mathrm{C}$ occur; (b) during temperature changes, the optics and the structure elongate or shrink by the same relative amounts, thus keeping the position of the focal point relative to the vertex of the primary mirror quite stable.

The general layout of the primary mirror cell resembles a triangle. At its upper side and to each of the three corners of this triangle are mounted one pair of hexapod struts. The total of six struts carry at their upper ends the secondary mirror cell (see Fig. 4). The BGMs 5 are mounted on the topside of the secondary mirror cells. The total mass of the secondary mirror assembly is about $100 \mathrm{~kg}$. Flexure in the telescope tube when tilting the telescope out of zenith is compensated for by passively tilting the entire secondary mirror assembly, which ensures that the focal point remains on the fibre for all elevations. With this construction, the secondary mirror could be aligned and fixed relative to the primary mirror with an angular error of $<10 \mu \mathrm{rad}$ and a positioning error of $<0.1 \mathrm{~mm}$.

To realize a tiltability of $30^{\circ}$ off zenith, one corner of the primary mirror cell is mounted via a stiff universal joint to a telescope "table". The other two corners of the primary mirror cell are connected with universal joints and motorized roller screw spindles to the telescope table. Costs are thereby saved, since expensive worm gears are avoided. By separately moving the corners with the spindle drives up and down, the specified tilt and azimuth angles can be reached with a reproducibility of $<25 \mu \mathrm{rad}$. After having reached a fairly stable temperature regime, the absolute positioning of the hexapod structure has an accuracy of better than $150 \mu \mathrm{rad}$.

The mounting tables of the lasers and of the telescopes are firmly attached to a common foundation, the latter being laid down directly onto the bed-rock below the observatory. The laser/telescope foundation is separated from that of the observatory building.

3.4.3 Focal boxes and CCD cameras. The primary and secondary mirrors work together in directing the backscattered light onto the front end of a $1.5 \mathrm{~mm}$ diameter fibre cable. This requires that the laser beam and the telescope LOS are aligned parallel. Misalignments of only $50 \mu \mathrm{rad}$ will lead to much reduced data quality on a field-of-view of $180 \mu \mathrm{rad}$. To avoid misalignment between the laser beam and the telescope LOS, a feedback loop controls the position of BGM 5. Input to the loop is derived from CCD camera images. To this end, a CCD camera is placed in the focal box near the image plane. It provides a real-time, 2-dimensional view of the intensity distribution of the backscattered light, in particular the laser beam axes relative to the telescope axes. To this end, light from low altitudes $(1.5-3 \mathrm{~km})$ is focused directly onto a highspeed 


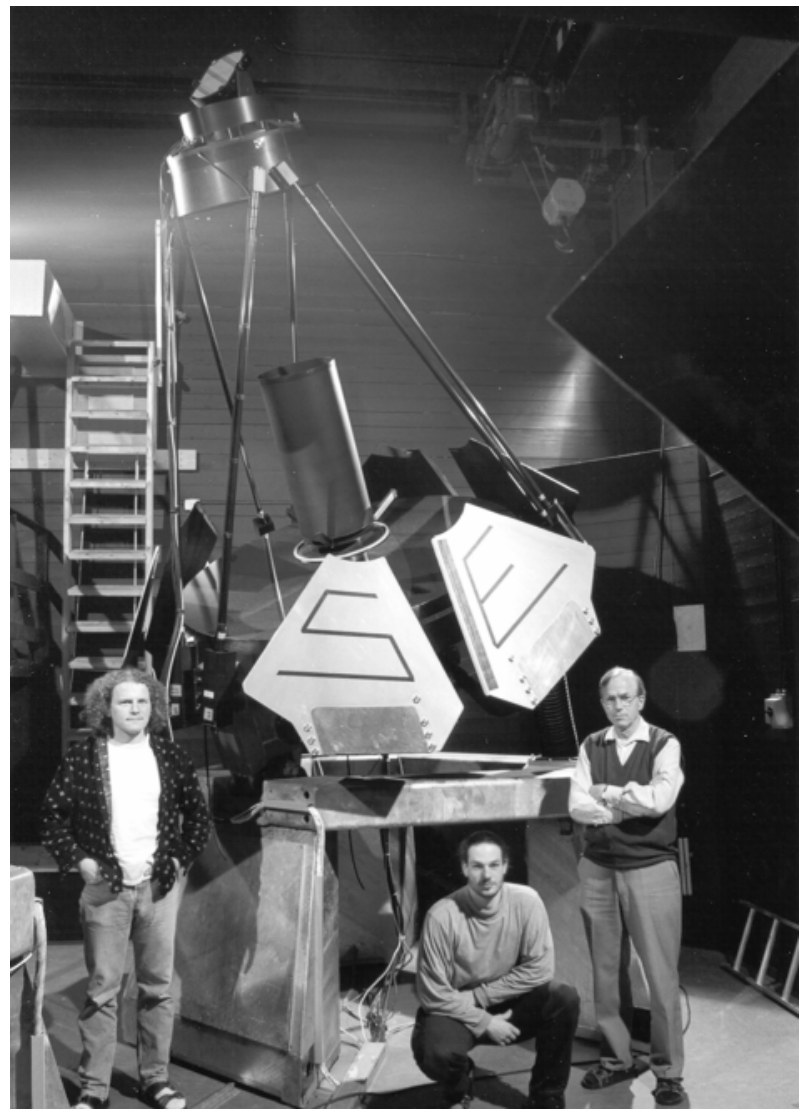

Fig. 4. The South-East telescope, in tilted position. In the centre of the figure are the $1.8 \mathrm{~m}$ primary and its light baffle. Six struts carry at their upper ends the secondary mirror cell and laser beam guiding mirror BGM 5. The primary is surrounded by six covers which can enclose the primary in less than $10 \mathrm{~s}$. By separately moving the corners of the primary mirror cell up and down with the spindle drives, the specified tilt and azimuth angles are reached. The tiltable structure of the telescope rests on a massive hexagonal table. Persons in front of the table are (from left to right) G. Baumgarten, D. Wagner, and U. von Zahn

CCD camera which is triggered at the laser pulse frequency. With this tool, it is possible to detect the actual laser beam position on a shot-by-shot basis.

Using this CCD camera with a variable FOV, two tasks are accomplished: (a) an initial alignment of the laser beam into the telescope axis even under full daylight conditions (which otherwise means "finding a needle in a haystack"); (b) automatic centering of the laser beam into the telescope FOV by feeding the output of the CCD camera into a regulation system which in turn controls the two axis motors of the BGM 5.

All movable components of the telescopes and in particular their focal boxes are motorized to allow their remote control from the operator's room. This includes the fast moving covers of the primary mirrors (which close in less than $10 \mathrm{~s}$ ) which are to protect the mirrors from snow or rain showers.

\subsection{Detection system}

The single detection system of the RMR twin lidar serves numerous tasks: a. Switching the light coming through either one of the telescope fibres into the detection system on a shot by shot basis

b. Suppression of low-altitude-signals by means of a mechanical chopper,

c. Separation of the photons into specific detector channels according to their wavelength, i.e.:

1. At the three emitted wavelengths of $1064 \mathrm{~nm}$, $532 \mathrm{~nm}$, and at $355 \mathrm{~nm}$, belonging to photons being Cabannes, or Mie scattered,

2. In wavelength bands near $530.4 \mathrm{~nm}$ and $529.1 \mathrm{~nm}$, belonging to photons which were rotationally Raman scattered on $\mathrm{N}_{2}+\mathrm{O}_{2}$,

3. At the wavelengths of $608 \mathrm{~nm}$ and $387 \mathrm{~nm}$ belonging to photons which were rotational-vibrationally Raman scattered on $\mathrm{N}_{2}$,

d. Separation into specific detector channels for photons with the same wavelength, but strongly differing intensity,

e. Spectral filtering of the various wavelength channels,

f. Counting the photons arriving at the various detectors.

3.5.1 Input assembly. The photons collected by the NWand SE-telescopes are transferred to the detection system via optical fibres. At the entrance of the detection system (see Fig. 5), the light from either fibre cable is alternately inserted into the optical path of the detection system by a rotary fibre selector. The rotary fibre selector consists basically of a continuously rotating disk which is half open and half covered by a mirror. Thus, during half a revolution the disk allows the light from the NW-telescope fibre to pass uninhibited into the detection system and during the other half revolution it mirrors the light from the SE-telescope fibre into the detection system. The rotary fibre selector is made to rotate synchronously with the laser pulses at $30.3 \mathrm{rev} \mathrm{s}^{-1}$ and to direct the photons collected from 60.6 laser pulses $\mathrm{s}^{-1}$ into the detection system.

The light diverging from the fibres is re-focused by the relay lenses L1 on a fast mechanical chopper which shutters the low-altitude signal. Then it is collimated by lenses L2 and passes through the dichroic beam splitters D1 and D2 which divide the light into the three principal branches, corresponding to 355, 532, and $1064 \mathrm{~nm}$. Both the relay and the collimator lens arrangements are specially designed to minimize chromatic aberration over the wide wavelength range 355 to $1064 \mathrm{~nm}$, while also minimizing both spherical and off-axis aberrations.

\subsubsection{Channels for observations of Cabannes and Mie} scatter. The broadest lidar signal is the Cabannes line, often incorrectly called "Rayleigh" line. According to Young (1982), Rayleigh scattering is the sum of Cabannes scattering (the central Doppler broadened line) and rotational Raman scattering (the side bands). In our application, Cabannes lines have, due to Doppler broadening, a full width at half maximum (FWHM) bandwidths of about of $1.6 \mathrm{pm}$ at $355 \mathrm{~nm}$ and $4.8 \mathrm{pm}$ at $1064 \mathrm{~nm}$. We note, though, that for reasons of briefness we keep just the word Rayleigh in the name of our instrument and some of its detector channels. 


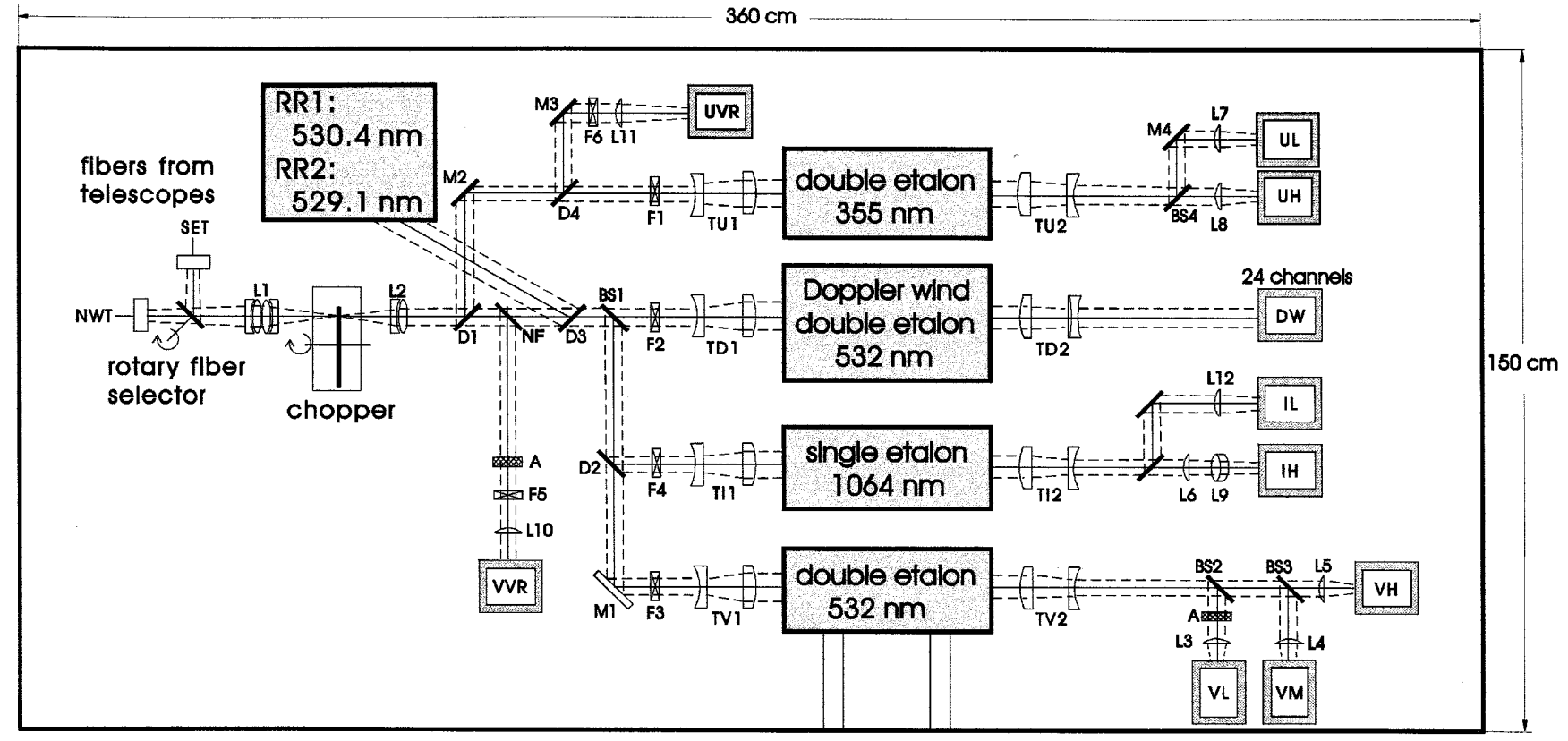

Fig. 5. Schematic of detection system. The photons collected by the NW- and SE-telescopes are transferred to the detection system via optical fibres. At the entrance (left side) the light from either fibre cable is alternately inserted into the optical path of the detection system by a rotary fibre selector. The light arriving from the fibres is re-focused by the relay lenses $L 1$ on a fast mechanical chopper. Then it is collimated by lenses $L 2$ and passes through the dichroic beam splitters $D 1$ and $D 2$ which divide the light into the three principal

In the RMR lidar, achieving high solar background suppression begins with the use of dielectric interference filters F1 through F4 with the narrowest practical bandwidths. We utilize interference filters with bandwidths of 0.3 to $0.5 \mathrm{~nm}$, made with "hard" dielectric technology, i.e. refractory metal oxides produced with ion assisted deposition. Still narrower spectral bandwidths are needed, however, and are permitted by the stability of the emitted wavelengths and the narrow spectral width of the backscatter signals. Spectral filters with bandwidths in the order of a picometer can be built, using Fabry-Perot etalon (Rees et al., 2000). However, the divergence of any light beam entering an etalon system has to be controlled carefully. The maximum acceptance angle of any Fabry-Perot interference filter, whether a large aperture etalon or a dielectric stack, is given by $n / \Re^{1 / 2}$, where $n$ is the index of refraction of the medium between the etalon plates and $\Re$ is the filter resolving power. In order to minimize degradation of the filter performance by the angular divergence of the illuminating beam, the beam divergence angle must be comfortably smaller than this maximum. In the RMR lidar, the beam has the following nominal parameters behind the entrance collimator: divergence of $\pm 4.7 \mathrm{mrad}$ and diameter of $35 \mathrm{~mm}$.

For even a high-resolution interference filter, such as our tenths-of-nanometer units, the maximum acceptable beam divergence is on the order of $45 \mathrm{mrad}$ : Thus, the residual divergence of our $35 \mathrm{~mm}$ diameter beam is branches, corresponding to 355 , 532, and $1064 \mathrm{~nm}$. Photons which were vibrationally Raman scattered on $\mathrm{N}_{2}$ are isolated by the notch filter $N F$ and interference filter $F 5$ (for $608 \mathrm{~nm}$ ) and the dichroic $D 4$ and interference filter $F 6$ (for $387 \mathrm{~nm}$ ). Rotationally scattered photons are isolated through dichroic D3. Each of the four etalon units is placed between beam widening and narrowing telescopes. The detector assembly $D W$ behind the Doppler wind etalon consists of 24 individual anodes

compatible with these filters. For the high-resolution Fabry-Perot etalons, however, the maximum angle is on the order of $2 \mathrm{mrad}$, and for DWTS is as small as $0.75 \mathrm{mrad}$ (per spectral channel). Consequently another stage of beam expansion is necessary to reduce the angular divergence. A Galilean telescope TD1 increases the beam diameter to $100 \mathrm{~mm}$, and decreases the divergence to $\pm 1.7 \mathrm{mrad}$. The light is coupled through antireflection-coated fused silica windows into cylindrical, temperature controlled, dry nitrogen filled, pressuresealed etalon housings (Rees et al., 1996), approximately $40 \mathrm{~cm}$ long and $36 \mathrm{~cm}$ in diameter. The etalon mounts permit two-axes adjustment of orientation, externally accessible, to provide exact alignment of both of the etalons with the optical axis. The etalon plate spacing and plate parallelism are adjusted and stabilized by piezoelectric stacks with capacitance stabilization. By remote control of two motors, the etalons are individually aligned to the common optical axis of the entire detection system. Baffling and optical black coating minimize scattered light bypassing the etalon filters within the housing. The light emerging from the etalon housings is reduced to the original $35 \mathrm{~mm}$ diameter by a reversed Galilean telescope TD2. This permits the use of a very high-quality interference filter F2 of affordable diameter and, in combination with an objective lens, a detector of practical aperture. Figure 6 shows the actual detection system (with top covers removed) looking from the detector side towards the input side of the optical table. 


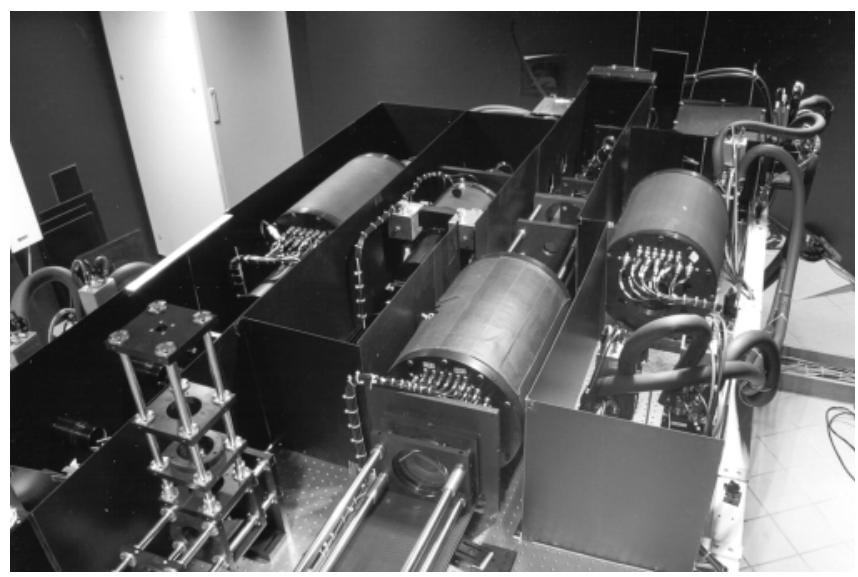

Fig. 6. Overview of the detection system, mounted on a $3.6 \times 1.5 \mathrm{~m}$ optical table, and with top covers removed. This view of the optical table is from the detector side towards the input side. From the left to right can be seen the housings of the $532 \mathrm{~nm}$ etalon, $1064 \mathrm{~nm}$ etalon, the DWTS etalon, and the $355 \mathrm{~nm}$ etalon. At the right upper corner is the "box" containing filters and the detectors for the rotational Raman channels RR1 and RR2

3.5.3 The RMR VIS Channel (532 $\mathrm{nm})$. In 1996, a double-etalon filter was installed in the $532 \mathrm{~nm}$ channels of the RMR lidar. The low-resolution etalon (LRE) is designed so that its free spectral range is somewhat larger than the $0.3 \mathrm{~nm}$ FWHM bandwidth of the interference filter, while reducing the effective combined spectral bandwidth by a factor 10 (Table 3 ). The optical path difference of the high-resolution etalon (HRE) is selected to minimize coincidences of the transmission maxima of the two etalons, while it reduces the effective spectral bandwidth by another order of magnitude. With an overall FWHM bandwidth of $4 \mathrm{pm}$, the filter/ interferometer combination provides a resolution of $\Delta \lambda / \lambda=1 / 130000$.

After having passed through its FP interferometer, the $532 \mathrm{~nm}$ signal consists only of Cabannes scattered photons. It is split into three channels of different sensitivity (VH, VM, and VL) in order to handle the large dynamic signal range. Furthermore, we use cooled photomultipliers in a photon counting mode as detectors.

As introduced in Sect. 2.2, an important application of the channels $\mathrm{VH}$ and $\mathrm{VM}$ is temperature profiling in atmospheric regions which do not contain aerosols or

Table 3. Summary of the solar filter parameters ( $L R E$, lowresolution etalon, $H R E$, high resolution etalon)

\begin{tabular}{lllll}
\hline Lidar channel & 1064 & 532 & 355 & 532 \\
& Ray/Mie & Ray/Mie & Ray/Mie & DWTS \\
\hline $\begin{array}{l}\text { Interference filter } \\
\quad \text { FWHM [nm] }\end{array}$ & 0.5 & 0.3 & 0.3 & 0.3 \\
$\begin{array}{l}\text { LRE } \\
\quad \text { optical gap [mm] }\end{array}$ & 4.000 & 0.216 & 0.111 & 2.325 \\
$\quad$ FSR [pm] & 140 & 655 & 570 & 61 \\
$\begin{array}{l}\text { HRE } \\
\quad \text { optical gap [mm] }\end{array}$ & - & 2.325 & 1.20 & 25.0 \\
$\quad-$ & 61 & 52 & 5.7 \\
$\quad$ FSR [pm] & - & 4 & 4 & 0.3 \\
\hline
\end{tabular}

cloud particles (typically above $30 \mathrm{~km}$ altitude). Another major application of the channel $\mathrm{VH}$ is measuring the backscatter coefficient of the particles in NLCs at $532 \mathrm{~nm}$ wavelength.

3.5.4 The RMR UV channel (355 nm). The UV channel is especially technically challenging. In daytime, the spectral radiance of the sky at $355 \mathrm{~nm}$ is higher than that at $532 \mathrm{~nm}$, the much stronger Rayleigh scattering more than offsetting the lower solar irradiance at $355 \mathrm{~nm}$. The optical path difference of the UV LRE is selected again to match the $0.3 \mathrm{~nm}$ FWHM bandwidth of the interference filter. The optical path difference of the UV HRE is larger by a factor of about 11. Ideally the pair of etalons will reduce the effective spectral bandwidth by more than a factor of 100 . In practice, the attenuation of the solar background is less than this, owing to optical imperfections. Examples of the current performance of this channel are given.

For the same reason as at the VIS channel, we split the backscattered signal at $355 \mathrm{~nm}$ into two channels of different sensitivity (UH and UL). Similarly, we use cooled photomultipliers in a photon counting mode as detectors.

As introduced in Sect. 2.2, an important application of the channel UH is temperature profiling in atmospheric regions which do not contain aerosols or cloud particles (typically above $30 \mathrm{~km}$ altitude). Another major application of the channel $\mathrm{UH}$ is measuring the backscatter coefficient of the particles in NLCs at $355 \mathrm{~nm}$ wavelength.

3.5.5 The RMR IR channel $(1064 \mathrm{~nm})$. As regards spectral filtering, the $1064 \mathrm{~nm}$ channel is the least demanding. Firstly, the solar irradiance is less than half its peak value around $500 \mathrm{~nm}$. Secondly, Rayleigh scattering is much weaker $\left(\lambda^{-4}\right)$. On the other hand, the Mie backscatter coefficients tends to vary as $\left(\lambda^{-1}\right)$, providing a better signal to noise ratio compared with, say, $532 \mathrm{~nm}$. This may be offset, however, by the lower detective quantum efficiency of photon counting detectors at $1064 \mathrm{~nm}$ in comparison to that at $532 \mathrm{~nm}$.

Taking these factors into account, a single etalon filter was designed, built, and implemented in June 1998 for solar filtering at $1064 \mathrm{~nm}$. The high defect finesse achievable at this longer wavelength permits the use of an etalon with higher reflectance finesse, and hence lower solar background transmittance (Table 3).

After having passed through its FP interferometer, the backscattered signal at $1064 \mathrm{~nm}$ is split into two different sensitivity channels. For detection of the lower and the higher altitude signals, we use a photomultiplier (IL) and avalanche photodiode (IH), respectively. The photodiode has a signal/noise ratio about 15 times better than that of the photomultiplier. Both detectors are cooled and work in a photon counting mode.

The major applications of the $1064 \mathrm{~nm}$ channel are in detecting weak stratospheric aerosol layers and in measuring the Mie backscatter coefficients of aerosol and cloud particles for the determination of the size distributions of these particles. 


\subsubsection{Channels of the Doppler wind and temperature} experiment. The first of the channels of the RMR lidar to be fitted with a double-etalon filter was the Doppler Wind and Temperature System (DWTS), commissioned in October 1994. The primary goal of the DWTS is wind vector measurement in the stratosphere via the Doppler shift of the Cabannes line (Rees et al., 1997). In this case the function of the HRE is not solar filtering but the analysis of the backscattered signal to determine the Doppler shift. Because the full free spectral range of the HRE is collected by the imaging detector, there is no attenuation of the broadband sky signal versus the spectrally narrow lidar signal. In order to reduce the background illumination without attenuating the signal, a LRE is used in combination with a $0.3 \mathrm{~nm}$ FWHM filter. The optical path difference of the LRE is then selected such that its free spectral range is roughly the geometric mean between the free spectral range of the HRE and the bandwidth of the interference filter.

A secondary purpose of the DWTS experiment will be to derive temperatures from the measurement of the Doppler width of the Cabannes line at $532 \mathrm{~nm}$. The development of this technique is ongoing and results will be presented in future publications.

For signal detection, DWTS uses the "fringe imaging" technique. This exploits the multiplex advantage of a low-noise imaging detector to increase instrument sensitivity, while avoiding the need to scan or step the etalon optical path difference to obtain the full spectrum of the backscattered signal. The wind detector DW employs a 24-channel photomultiplier, using (a) a photocathode, (b) proximity focused micro-channel plate intensifier, and (c) discrete-element anode. The 24 individual anode elements of the detector are shaped as concentric annular rings, to match equal-wavelength intervals of the Fabry-Perot spectrum. The entire imaging detector is operated in a photon-counting mode.

A high-performance signal processing system is used to handle the 24 spectral channels of data, providing 512 range bins samples at typically $200 \mathrm{~m}$ range resolution. An example of a Doppler wind measurement is presented in Sect. 5.3.

3.5.7. Channels for observations of Raman scatter. The $\mathrm{N}_{2}$ rotational-vibrational Raman channels at 608 and $387 \mathrm{~nm}$ (VVR and UVR), corresponding respectively to excitation by $532 \mathrm{~nm}$ and $355 \mathrm{~nm}$ photons, are separated from their corresponding Cabannes lines by dichroic filters NF and D4 and are selected by 0.3 and $0.9 \mathrm{~nm}$ FWHM bandwidth interference filters F5 and F6, respectively.

The major applications of the channels VVR and UVR are in temperature profiling under conditions of a light aerosol load and in measuring the extinction coefficients in aerosol layers.

Measurements using the $\mathrm{N}_{2}+\mathrm{O}_{2}$ rotational Raman channels centred at 530.4 and $529.1 \mathrm{~nm}$ are especially challenging due to the spectral proximity of the $532 \mathrm{~nm}$ Cabannes and Mie lines which are more than 3 orders of magnitude stronger and require to be very carefully rejected (Nedeljkovic et al., 1993). This is accomplished using a series of four dichroic filters. The first of the filters (D3) separates the anti-Stokes rotational Raman lines from other wavelengths and sends it into the "Raman box" (Fig. 5). The remaining three filters separate the two components of the rotational Raman spectrum and increase successively the rejection of the Cabannes and Mie lines. The final selection of the two wavelengths is obtained using interference filters with bandwidth of $0.6 \mathrm{~nm}$. A total of $10^{-7}$ rejection of the $532 \mathrm{~nm}$ Cabannes scattering is obtained. For maintaining a high efficiency of the entire filtering process, a temperature stabilisation of the entire Raman box is required.

The most important application of the channels RR1 and RR2 is in measuring the air temperature in those layers below $30 \mathrm{~km}$ altitude which contain enough aerosol and/or cloud particles to cause strong extinction.

\subsection{Data acquisition and lidar control}

The data acquisition electronics includes 12 photon counting channels. Each channel has its own internal quartz oscillator. The range resolution may be adjusted for each channel from a minimum value of $50 \mathrm{~m}$ and is normally set to $150 \mathrm{~m}$. The signal is accumulated in 4096 altitude steps, 2048 for each of the telescopes, and sent to the computer after integrating over a predefined number of laser pulses (typically 250). The software for (a) control of the detector functions (e.g. level of and electronic shuttering of the high voltages to the multipliers), (b) quality check of the acquired signals, (c) realtime display of the backscatter profiles, and (d) data storage is installed on a Unix computer. This computer and its operator are assisted in running the entire lidar system by an additional 10 PCs and seven camera systems (two for control of the directions of the laser beams before beam widening; two for locating the positions of laser beams with respect to the telescope axes; mechanical status of telescopes; condition of roof of telescope hall; all-sky). To this end, the Unix computer interfaces with several subsystems, such as laser computer, telescope computer, interfaces to detection system, and data acquisition electronics. Most importantly, the signals presummed by the acquisition electronics are transferred to the Unix computer and summed there during 1 to 3 min sequences (=1 record) and stored on the computer disk.

A "user-friendly" computer interface allows the operator to define the parameters for acquisition and operation and to control the status of the lidar. The display shows the raw signal for all channels and an indicator of signal quality (mean signal level at a reference altitude and the mean background), the progress of laser pulses and alarm reports when needed.

In order to increase its opportunities for observations, we have provided the RMR lidar with a marginal weather mode of operations. In this mode, the data system is continuously testing in real-time whether for any presummation period (typically $8 \mathrm{~s}$ long) the signals received from the stratosphere are above a certain 
preselected level of intensity. All data, which does not meet this minimum signal criterion, are discarded before storage in the data bank.

\section{Experiences in operating the lidar}

\subsection{Positive experiences}

Using the steerable laser beams to find the narrow FOV of receiving telescopes has proven to be a difficult task in many of the earlier nighttime lidar experiments. In the case of the RMR lidar, this task has be performed routinely in daylight and with even narrower FOV and smaller laser beam divergence than in common lidars. To make this task manageable, we have built the foundations for the lasers and telescopes directly onto the bed-rock of the Ramnan Mountain. In addition, the CCD cameras near the image plane of the telescopes (see Sect. 3.4) give the lidar operator a much wider FOV than used for collecting the backscattered photons. These two measures have proven very effective in that the laser beam is typically in the (wide) FOV of the CCD camera right at turn-on of the lidar. Finealignment of the laser beam into the axis of the (narrow) detection FOV is then a matter of a few minutes.

The recently developed capability of the RMR lidar to keep its laser beams automatically centred on the LOS of the telescopes, is another major advance in lidar operations. It improves the quality of the collected data and relaxes considerably the attention that the operator has to pay to the instrument. Experiences with this CCD tracking system show that even in cases of strong differential temperature changes across the telescope structure, the feed back regulation allows the system to run totally automatically. Furthermore, the camera system gives a good estimation of atmospheric turbulence and serves as a warning system for fast changes of atmospheric conditions.

The mode for data collection in marginal weather conditions (see Sect. 3.6) has also proven very useful, in particular in the presence of thin cirrus layers or fields of broken clouds. Availability of this operation mode has considerably enhanced the observation statistics of the RMR lidar. For example, it made it possible to obtain lidar observations during the 1998 NLC season (June 1 until August 15) for $389 \mathrm{~h}$, which is $21 \%$ of the entire period (von Cossart et al., 1999).

Reliability of the instrument is excellent. This statement applies, fortunately, to both its hardware and software. The optical alignment of the lasers, the frequency doubling and tripling devices, the beam direction stabilization and their beam widening telescopes are so stable that maintenance work is performed only at three to four month intervals. Availability of the telescopes, including their tilting capability, for lidar observations is virtually $100 \%$. Most of the extensive equipment mounted on an optical table, including the four Fabry-Perot interferometers, work reliably. Problems crop up now and then with some of the photon-counting multipliers and/or their cooling systems about which we briefly report later. The large volume of software, which is required to control the instrument and to handle its data, works extremely well. This seems notable as the package constantly evolves with the various upgrades of the instrument capabilities.

The excellent overall reliability of the instrument is the foundation for the good observation record of the lidar. It also has enabled us to perform, e.g. uninterrupted atmospheric observations for periods of up to $50 \mathrm{~h}$. Its high reliability in combination with a large degree of automation is also a prerequisite for cutting down the man power requirement for operating the lidar to one engineer only.

There is one more pleasant experience worth mentioning: it is the fact that the short distance of only a few kilometres between the RMR lidar and the busy Andenes airport has not led to any negative impact on the lidar observations.

\subsection{Unexpected obstacles}

Naturally, there were some obstacles to overcome during the development and operation phases of the RMR lidar. For the lasers, there were two of them: (1) to procure mirrors and lenses, the special coatings of which could stand the extreme power densities of the threecolour laser beams of the GCR-6, one of which is a UV beam. Solving this problem took us about two years; (2) to provide cooling water with a tightly controlled temperature at the laser heads (see Sect. 3.2) turned out to be a major challenge. The problem was aggravated by the fact that the load of the observatory provided cooling water system and of the ambient air temperature are both quite variable. The current solution for the power lasers of the RMR lidar is to put three separately controlled loops of cooled fluids in series, the last one of them providing cooling water to the laser heads with a temperature stability of $\pm 0.2{ }^{\circ} \mathrm{C}$ under any operating conditions.

In the area of the telescopes, we experienced only one, but rather major obstacle. We had assumed that the $1.8 \mathrm{~m}$ diameter primary mirrors, which were made available to us, were of perfectly spherical shape. Only after the secondaries were machined and the first telescope completely assembled inside the ALOMAR observatory, did we then find out that the primary mirrors were aspherical enough that an acceptable quality of the image was impossible to achieve with the initial mirror combination. Thus, new secondary mirrors had to be made for both telescopes and since their installation in the telescopes, the latter are working fine.

The detection system provided three obstacles, only one of which has been overcome so far: (1) optical and electrical interference between the numerous detector channels. It required a multi-year effort to finally eliminate any interference between the total of 36 detector channels which we operate within the detection system. We consider this problem solved (even though it 
still needs constant attention). (2) Development of a systematic alignment procedure for the multitude of optical channels and components on the optical table of the detection system. On the one hand, this equipment is working reasonably well as proven by the number of publications resulting from the data processed in this detection system. On the other hand, optimizing the alignment procedures for all of the equipment on the optical table is a long-term project and has certainly not yet come to an end. (3) At the observatory site, the relative humidity of the ambient air is usually high. At the same time, many of the detectors on the optical table need active cooling to minimize their background count rate. This scenario has led to numerous problems caused by condensation of water vapour on and in multiplier housings and high-voltage devices and/or corrosion of bare metal surfaces. Partial solutions for this problem have been realized, but a perfect one is still outstanding.

\section{Instrument performance}

\subsection{Laser performance}

The transmitter system of the RMR lidar works quite reliably with the performance parameters shown in Table 2. Maintenance work is performed about three times per year. To guarantee maximum stability of the seeder laser, this laser and its wavelength control loop operate continuously.

To quantify the residual fluctuations in laser beam direction, Fiedler and von Cossart (1999) registered the positions of mirrors BGM 1 and 2, the diameter of the reference path laser beam at the CCD camera, and the temperature of the second pump chamber of the laser amplifier during an 18-h lidar run. From the observed behaviour, they calculated temperature dependencies of the beam axis stability and beam divergence. The residual fluctuations of the laser beam were determined to remain within $\pm 10 \mu \mathrm{rad}$ for more than $81 \%$ of the time in horizontal and for more than $85 \%$ of the time in the vertical axis (see Fig. 7). Nearly all laser pulses remain within $\pm 20 \mu \mathrm{rad}$ for both axes.

\subsection{Telescope performance and capabilities}

One important performance figure for the telescopes is the time needed to change the direction of observations, including re-acquisition of the laser beam in the FOV of the telescope. This time is typically less than $5 \mathrm{~min}$ for a change of direction by $30^{\circ}$.

The capability of the RMR lidar for off-zenith measurements has been used for example to point the LOS of one of our telescopes close to the ascending trajectories of the NASA sounding rockets DROPPS/ PMSE and DROPPS/NLC, which were launched from the Andøya Rocket Range on July 6 and 14, 1999, respectively. The tilt of the lidar telescope allows us to bring closely together the volumes sampled in situ by the

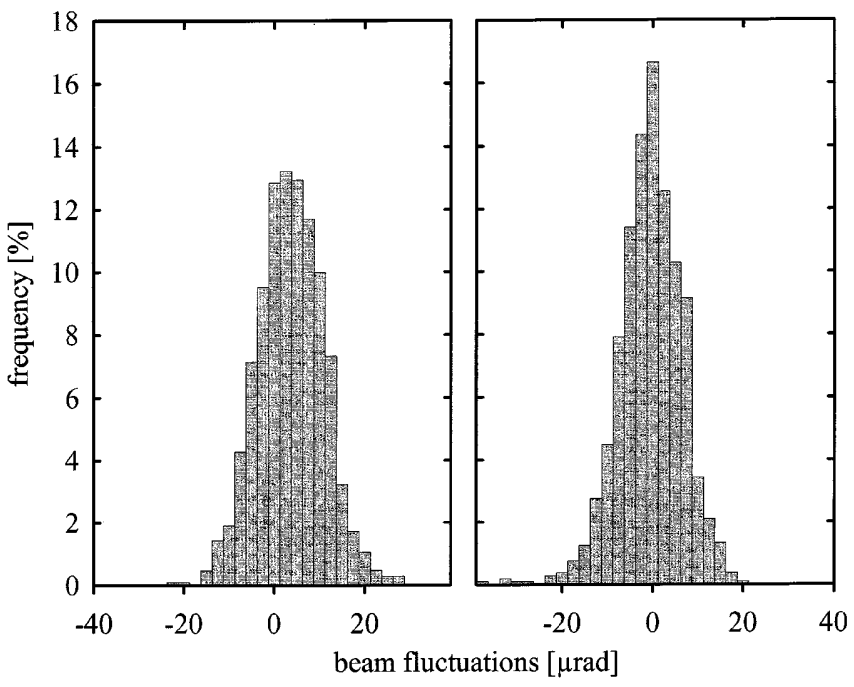

Fig. 7. The frequency distribution of the residual fluctuations in laser beam directions while the control loop is in operation (left panel: horizontal axis; right panel: vertical axis). The residual fluctuations of the laser beam remain within $\pm 10 \mu \mathrm{rad}$ for more than $81 \%$ of the time in horizontal and for more than $85 \%$ of the time in the vertical axis. Nearly all laser pulses remain within $\pm 20 \mu \mathrm{rad}$ for both axes

rocket experiments and remotely by the lidar. For the two DROPPS payloads, they penetrated NLC layers just 3 and $7 \mathrm{~km}$, respectively, away horizontally from the lidar-sampled volumes. However, it should be noted that even these remaining small separations were mostly caused by last-minute adjustments of the nominal launch azimuth of the sounding rockets which were not passed on to the RMR lidar operator.

\subsection{Detection system performance}

Figure 8 demonstrates the performance of the multichannel detection system with respect to interferencefree operation of 11 detector channels showing the number of photon counts per laser pulse and $1 \mathrm{~km}$ altitude during one night of observations versus altitude. The simultaneously operating channels can be separated into (a) the high sensitivity, high-altitude channels for Cabannes and Mie scatter at $532 \mathrm{~nm}(\mathrm{VH})$ and $355 \mathrm{~nm}$ (UH); (b) the main IR channel for Cabannes and Mie scatter at $1064 \mathrm{~nm}$ (IL); (c) the three low sensitivity, stratospheric channels for Cabannes and Mie scatter at $532 \mathrm{~nm}$ (VM and VL) and $355 \mathrm{~nm}$ (UL); (d) the two rotational-vibrational Raman channels from $\mathrm{N}_{2}$ at $608 \mathrm{~nm}$ (VVR) and $387 \mathrm{~nm}$ (UVR); the two rotational Raman channels from $\mathrm{N}_{2}+\mathrm{O}_{2}$ near 530.4 (RR1) and $529.1 \mathrm{~nm}$ (RR2); and (e) the DP channel indicating the amount of cross-polarization at $532 \mathrm{~nm}$. Not shown in this figure are the simultaneously collected profiles from the 24 DWTS detectors.

Photons backscattered from altitudes below $8 \mathrm{~km}$ are blocked by the mechanical chopper from reaching the detectors, in order to protect the photocathodes from the high photon flux backscattered in the troposphere. 


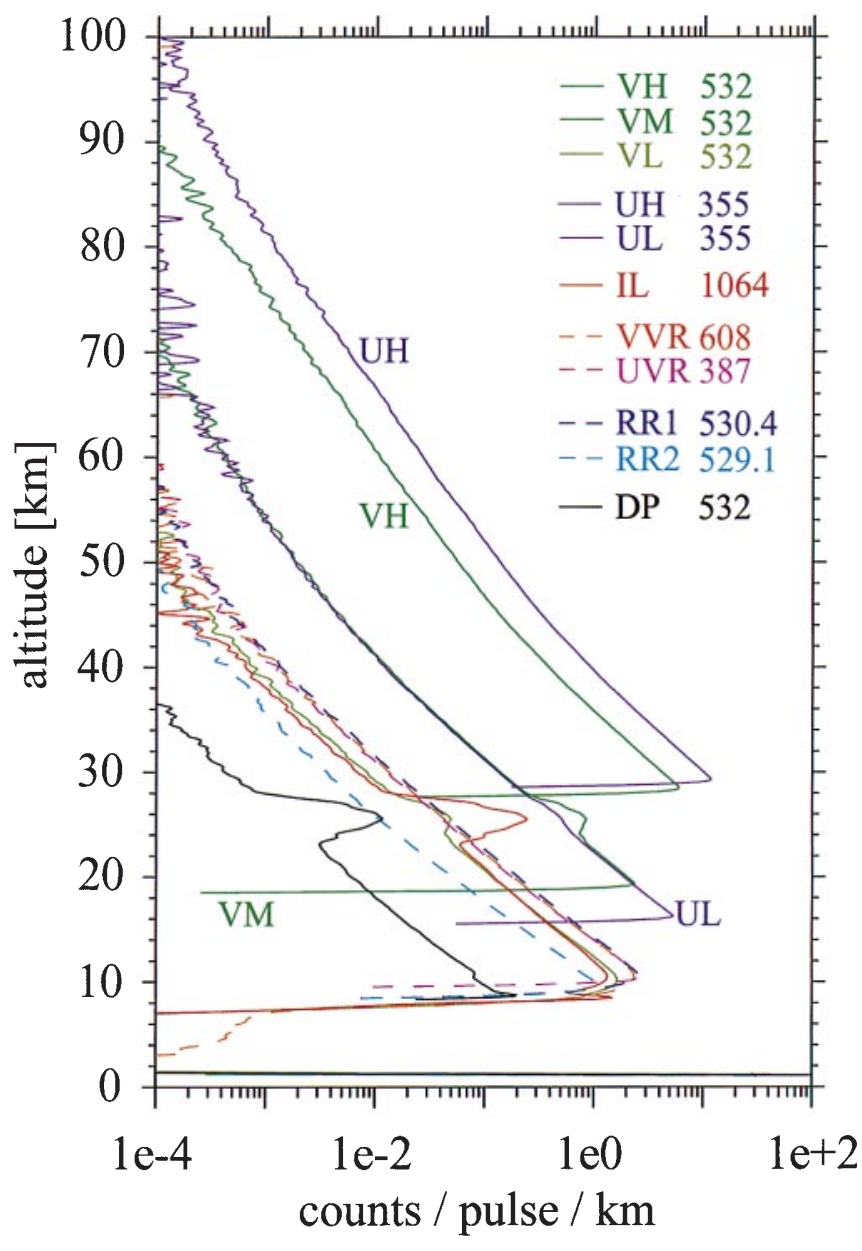

Fig. 8. Performance of the multichannel detector system, including the altitude profiles for 11 detector channels using 7 different wavelengths (for details, see text). The simultaneously collected profiles from the 24 DWTS detectors are not shown. The counts were integrated during the night of January 7/8, 1997 over the period from 20:01 UT until 05:19 UT. Photons backscattered from altitudes below $8 \mathrm{~km}$ are blocked by the mechanical chopper from reaching the detectors. In addition, for a number of the detector channels, electronic shuttering of the multipliers prevent high currents in the photomultiplier chain of dynodes. Between 23 and $28 \mathrm{~km}$ altitude, a polar stratospheric cloud produces Mie scatter in the (from left to right) $D P, V L, I L, U L$, and $V M$ channels. At the same altitudes, the vibrational $(V V R, U V R)$ and rotational $(R R 1, R R 2)$ Raman channels show no Mie backscattered signal. The cloud signature in the $D P$ channel indicates that the scattering cloud particles are of non-spherical shape

In addition, for a number of the detector channels, electronic shuttering of the multipliers prevents high currents in the photomultiplier chain of dynodes. Between 23 and $28 \mathrm{~km}$ altitude, a polar stratospheric cloud produces Mie scatter in the DP, VL, IL, UL, and VM channels (from left to right). At the same altitudes, the rotational-vibrational (VVR, UVR) and rotational (RR1 and RR2) Raman channels show no Mie backscattered signal. The cloud signature in the DP channel indicates that the scattering cloud particles are of nonspherical shape. All channels show the general decrease of signal strength with increasing altitude, which is due mostly to the decreasing air density and to a lesser degree the increasing distance between the scatter volumes and the receiving telescopes. All of the channels are free from electronic spikes or inter-channel interference.

\subsection{Overall lidar performance}

The overall detection sensitivity of any lidar system can be expressed e.g. by the number of photon counts per laser pulse per altitude interval received from a reference altitude. We take as reference altitude that of $30 \mathrm{~km}$ where the signal comes from Rayleigh scatter on air molecules only (and negligible Mie scatter). If we take the laser energy per pulse as $360 \mathrm{~mJ}$ at $532 \mathrm{~nm}$ and all transmissivities through optical components and the atmosphere equal 1 , one can calculate an idealized figure-of-merit of 64350 counts $/$ pulse $/ \mathrm{km}$. In real life, this figure-of-merit is currently about 20 to 25 counts/ pulse $/ \mathrm{km}$ the for the $532 \mathrm{~nm}$ Rayleigh channel VH of the ALOMAR RMR lidar (while working with the double etalon system).

On first sight, the observed figure-of-merit may not be as high as one would expect considering the large mirrors of the telescopes. However, providing simultaneously the capabilities for daylight observations, for three wavelengths observations, and for wind measurements results in a considerable complexity of the optical design of the lidar. For example, the $532 \mathrm{~nm}$ photons, which produce the signals in the $\mathrm{VH}$ channel, pass between their exit from the laser and conversion to an electron cascade in the photomultiplier no less than 12 reflecting mirrors (including beam splitter BS1), 27 transmitting components having 54 surfaces, and a number of lossy media such as the atmosphere (twice), the glass fibre between telescope and detection system, 2 beam splitters, 2 dichroics, 1 interference filter, and the double-etalon. In Table 4a we provide our best estimates for the transmission efficiencies of the four major components of the lidar systems: (1) the transport of the laser photons from the laser output into the atmosphere; (2) the 2-way transmission through the atmosphere (as effected by Rayleigh and Mie scatter); (3) the efficiencies of the receiving telescopes and fibre cables; and (4) the detection efficiency. Evidently the most dramatic losses of photons occur in the detection system. It is for this reason, that we provide in Table $4 \mathrm{~b}$ our best estimates for the efficiencies of the various components in the detection system. For an identification of these components, we refer to Fig. 5. There are five components in the detection system with efficiencies smaller than 0.85: The dichroic D3 (which is to separate $530.4 \mathrm{~nm}$ from $532 \mathrm{~nm}$ ), the beam splitter BS1 (which divides the photon stream 50/50 for wind and for Rayleigh/Mie observations), the filter F3, the double etalon (required for daylight observations), and the quantum efficiency of the photomultiplier. The product of efficiencies of only these five components is already as small as 0.018 .

If we multiply the noted "idealized" figure-of-merit with the estimated overall lidar efficiency of 0.0011 
Table 4. Efficiencies for photon throughput: (a) system efficiencies; (b) component efficiencies of detection system for the $532 \mathrm{~nm} \mathrm{VH}$ channel

\begin{tabular}{ll}
\hline & \\
\hline (a) System & Efficiency \\
Laser beam into atmosphere & \\
2-way transmission through atmosphere & 0.5 \\
Telescopes and fibre cables & 0.4 \\
Detection system for VH channel & 0.67 \\
Overall lidar efficiency (theoretical) & 0.0083 \\
(b) Component & 0.0011 \\
Rotary Fibre Selector & \\
L1 (8 surfaces @ 0.99) & 0.90 \\
L2 (4 surfaces @ 0.99) & 0.923 \\
D1 dichroic & 0.961 \\
NF dichroic & 0.99 \\
D3 dichroic & 0.97 \\
BS1 beam splitter & 0.80 \\
D2 dichroic & 0.50 \\
M1 mirror & 0.90 \\
F3 interference filter & 0.99 \\
TV1 entrance telescope (4 surfaces @ 0.99) & 0.49 \\
Windows of FPI housing (4 surfaces @ 0.99) & 0.961 \\
Etalon transmission (2 @ 0.7) & 0.961 \\
FPI plates (4 backside surfaces @ 0.99) & 0.49 \\
TV2 exit telescope (4 surfaces @ 0.99) & 0.961 \\
Transmission through 5 cm of BK7 glass & 0.961 \\
BS2 beam splitter & 0.992 \\
BS3 beam splitter & 0.97 \\
L5 objective (2 surfaces @ 0.99) & 0.95 \\
Multiplier tube window (2 surfaces @ 0.96) & 0.98 \\
Multiplier quantum efficiency & 0.922 \\
Overall detection efficiency & 0.18 \\
& 0.0083 \\
\hline
\end{tabular}

(Table 4a), we obtain a predicted figure-of-merit of 73 counts $/$ pulse $/ \mathrm{km}$ versus the observed 20 to 25 counts/ pulse $/ \mathrm{km}$. We are content with the factor of 3 difference between the two values because the properties of almost 50 optical components and lossy media contribute with their uncertainties to the error of the predicted figureof-merit.

Providing the capabilities for daylight observations and for rotational Raman temperature and wind measurements results in losses of intensity by factors of 0.29 and 0.41 , respectively, in the Rayleigh channels $\mathrm{VH}$, $\mathrm{VM}$, and VL; the capability for three-wavelengths transmission results in a loss of the intensity at $532 \mathrm{~nm}$ by a factor 0.52 with respect to a two-wavelengths operation. Thus, providing the noted three capabilities simultaneously, as the RMR lidar does, cuts the intensity at the commonly used $532 \mathrm{~nm}$ channel by a factor 0.06. Hence, if we concentrate on nighttime observations in the vertical at $532 \mathrm{~nm}$ without Doppler wind capability only, the figure-of-merit for the RMR lidar would be expected to fall between 320 and 400 counts $/$ pulse $/ \mathrm{km}$ from $30 \mathrm{~km}$ altitude.

\subsection{Examples of observations}

The excellent capabilities for daylight observations of the RMR lidar are highlighted by Fig. 9. The data were collected during an NLC event overhead the ALOMAR observatory on July 16,1998 . The signals were integrated for $2.8 \mathrm{~h}$. During the integration time, the Sun was continuously above the horizon and its elevation angle varied from $26^{\circ}$ to $12^{\circ}$. The profiles of normalized counts for the three wavelengths 1064, 532, and $355 \mathrm{~nm}$ are shown. The normalized counts are obtained by dividing the counts received from altitude $z$ by those received from $35 \mathrm{~km}$ altitude. The NLC layer is clearly seen in all three colours. The signal-over-background ratio is the best in the $532 \mathrm{~nm}$ channel; the background is dominated in the IR channel by detector noise, in the UV channel by scattered solar photons. From data like these, von Cossart et al. (1999) have derived, for the first time, three-parameter size distributions for NLC particles.

Figure 10 demonstrates the performance of the $532 \mathrm{~nm}$ VH channel with respect to the background skylight throughout a diurnal cycle. The signals caused by laser photons (L) backscattered from air molecules at $50 \mathrm{~km}$ altitude plus the solar background (S) versus the Sun elevation angle $\left(0^{\circ}=\right.$ sun at horizon) are shown. The data are taken from every tenth integration period, each one being $3 \mathrm{~min}$ long, and are converted to (counts $/$ pulse $/ \mathrm{km}$ ) on the left ordinate axis and presented as (counts $/ 3 \mathrm{~min} / \mathrm{km}$ ) on the right ordinate axis. We add that the noise level of the photomultiplier is about $5 \mathrm{~Hz}$ which is equivalent to $3 \times 10^{-5}$ (counts/ pulse $/ \mathrm{km})$.

At our site, the sky is almost never clear $(=$ dark blue) in summer. Haze and/or a thin tropopause cirrus are frequently present. The effectiveness of the elimination of solar background is, however, strongly dependent of the amount of haze or cirrus above the lidar site. Under "normal conditions" at ALOMAR, these particles enhance significantly the solar background by Mie scatter, decrease the Rayleigh backscatter signal by extinction, and may introduce a significant temporal variability into the laser backscatter and solar background signal. For these reasons, the solar background signal does not lend itself to a theoretical calculation. The data shown in Fig. 10 should be taken as those of a "normal" ALOMAR late summer day. The difference in signal strength before and past noon at sun elevation angles about $20^{\circ}$ is caused by a difference in atmospheric transmission (which is NOT eliminated from the data shown). The short term variability of transmission can be judged from the steadiness of the 3-min data points. The variability is small enough to work in full daylight with laser backscatter signals received from altitudes well above $50 \mathrm{~km}$ with integration periods as short as $10 \mathrm{~min}$.

Figure 11 shows the result of a Doppler wind measurement by the DWTS experiment, performed January 9, 1998. There are three profiles shown of the zonal component of the wind velocity. Integration times were about $10 \mathrm{~min}$ per profile. This examples demonstrates qualitatively a good reproducibility of the measured profile combined with some geophysical variability of the wind field. The error bar at $30 \mathrm{~km}$ altitude is $\pm 2 \mathrm{~m} / \mathrm{s}$. 


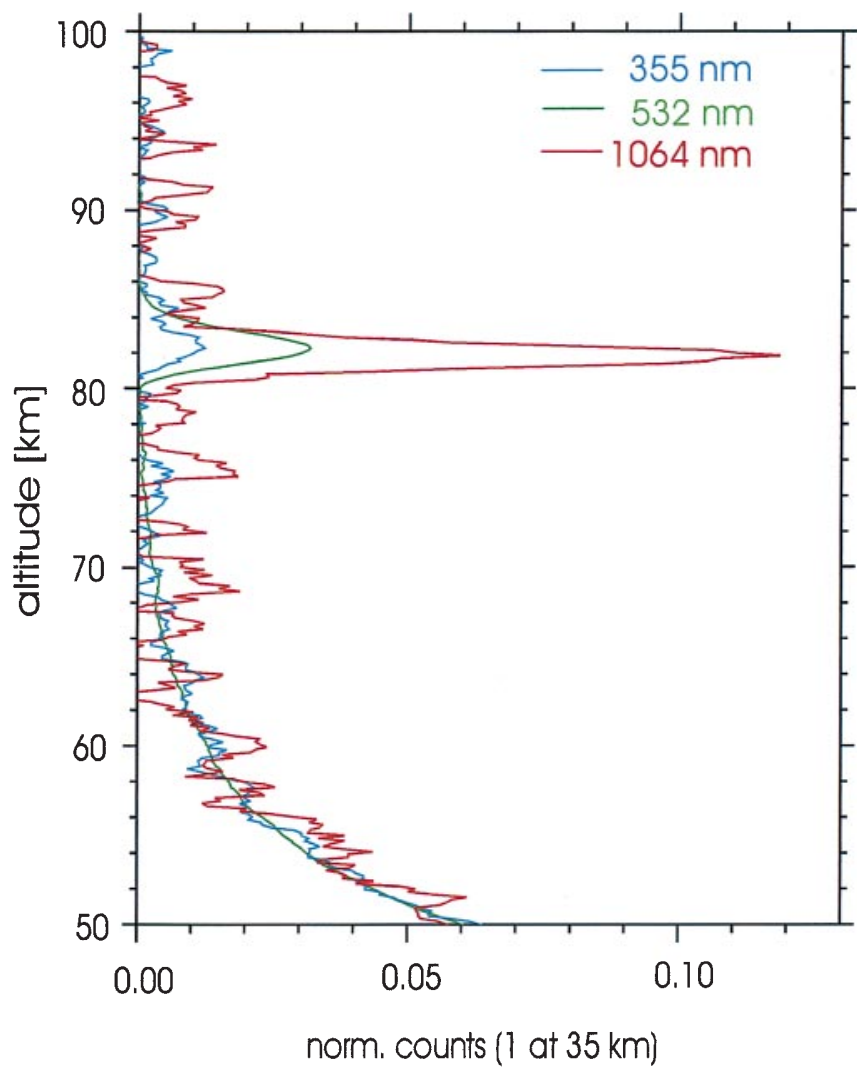

Fig. 9. A daylight, 3-colour NLC observation. The data were collected July 16, 1998, during a NLC event overhead the ALOMAR observatory. The signals were integrated for $2.8 \mathrm{~h}$. During the integration time, the sun was continuously above the horizon and its elevation angle varied from $26^{\circ}$ to $12^{\circ}$. Shown are the profiles of normalized counts (see text) for the three wavelengths 1064,532 , and $355 \mathrm{~nm}$. The NLC layer is clearly seen in all three colours

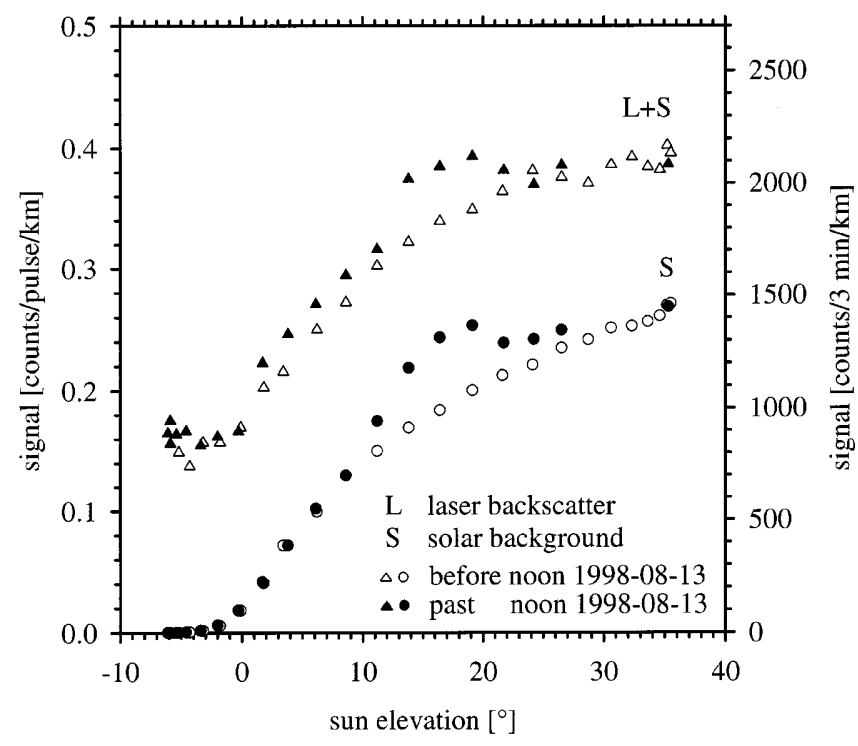

Fig. 10. Signals from backscattered laser photons $(L)$ and solar background $(S)$ versus solar elevation angle on August 13, 1998. The laser backscatter signal is taken from the altitude range 49.5 to $50.5 \mathrm{~km}$. Individual data points are derived from $3 \mathrm{~min}$ integration intervals. The solar background was calculated from the signals registered from 150 to $200 \mathrm{~km}$ altitude. Solar elevation angles were calculated neglecting any atmospheric refraction effects

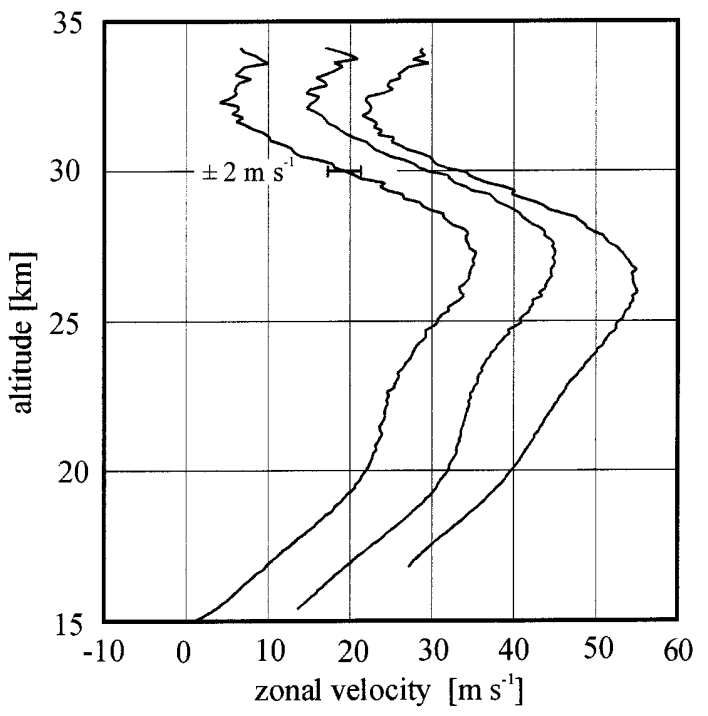

Fig. 11. Doppler wind measurements by the DWTS experiment, performed January 9, 1998. Shown are three profiles of the zonal component of the wind velocity. Integration times were about $10 \mathrm{~min}$ per profile. The velocity scale at the abscissa applies to the leftmost profile, all following profiles are offset to the right by $10 \mathrm{~m} \mathrm{~s}^{-1}$

\subsection{Automatic data processing}

We use two kinds of lidar data processing which run automatically and do not require user inputs:

a. An online processing capacity is installed at a PC nearby the data acquisition and control system allowing the operator to observe the ongoing measurement at a higher evaluation level. This is especially useful during detections of polar stratospheric clouds as well as noctilucent clouds. The display is continuously updated after each new data record. A time sequence plot which covers $24 \mathrm{~h}$ gives the operator a better overview about the measurements. This online information is also quite useful to assist rocket experiments taking place at the Andøya Rocket Range. To this end we have set-up a web-server for the RMR lidar for accessing the graphics output over the Internet.

b. Offline processing is performed each morning at 07 LT at the IAP at Kühlungsborn, Germany. The lidar data collected during the last $24 \mathrm{~h}$ are transferred via Internet from ALOMAR observatory to the IAP and processed there automatically. In addition, night mean temperature profiles are calculated. To this end, data from the various wavelengths and sensitivity channels are combined to yield a "best" temperature profile. The profiles start at the altitude of $30 \mathrm{~km}$, above which the assumption of negligible Mie scatter is justified. The upper end of the profile is determined by the computer from the criterion that the error bar should not exceed $\pm 5 \mathrm{~K}$. The profile is archived at the IAP and at the same time transmitted via e-mail to interested scientists and institutions. They use this nearreal-time information for e.g. their predictions of stratospheric warmings, the likelihood for occurrence of polar stratospheric clouds, or for improving stratospheric weather analyses. 


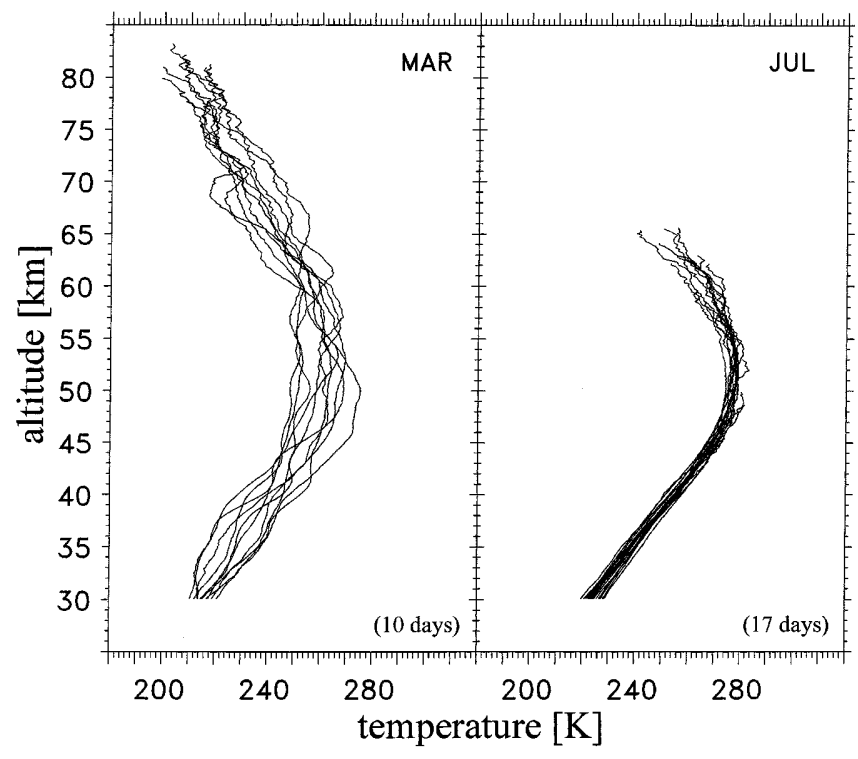

Fig. 12. Examples of automatically processed temperature profiles, including daily mean profiles obtained by the RMR lidar during darkness in March 1998 and during daytime in July 1998. The upper end of the profiles is chosen at an altitude where the statistical error bar reaches $\pm 5 \mathrm{~K}$

Examples of automatically processed daily mean temperature profiles are shown in Fig. 12. They were obtained by the RMR lidar during darkness in March 1998 and during daytime in July 1998. Due to the heavy solar background during summer observations, the July profiles do not reach as high as those gathered in wintertime. The character of the profiles indicates a clear difference in wave activity between the March ( = winter) and July (= summer) examples.

\subsection{Science results}

As noted in the Introduction, we append a list of reference with selected papers dealing with scientific results obtained by using the RMR lidar.

\section{Conclusions}

The ALOMAR Rayleigh/Mie/Raman lidar has established itself as one of the most capable lidars for remote sensing of the middle atmosphere. To our knowledge, it is the first Rayleigh lidar which sounds the middle atmosphere routinely in daylight and does so in three widely separated wavelengths. Its multiwavelengths capabilities allow for studies of complex phenomena such as physical and chemical properties of aerosol and cloud particles, at the time providing a number of internal consistency checks for e.g. the measured temperature profiles. It serves as a powerful testbed for the development of state-of-the-art technologies for Doppler wind measurements. Even though operating in the demanding environment of the Arctic, its high reliability and semi-automatic mode of operation allow us to collect a dense set of atmospheric soundings. The semi-automatic mode of operation includes a significant amount of real-time data processing and data distribution into e-mail and web links. Last but not the least, we suggest that many of its unique capabilities came about through pooling the experiences and resources of a multinational team.

Acknowledgements. The ALOMAR RMR lidar team acknowledges with sincere thanks outstanding efforts on behalf of the RMR lidar development by D. Antonov (CNRS/IAP), M. Enke (IAP), W. Eriksen (ARR/IAP), F. Fassina (CNRS), F. Hübner (BU/IAP), R. Lyngra (ARR), D. Nedeljkovic (CNRS), P.E. Nilsen (ARR/ IAP), V. Nussbaumer (BU), J.P. Marcovici (CNRS), N. Meredith (UCL), L. Olsen (ARR), J. Porteneuve (CNRS), T. Schlüter (BU), J. Siebert (BU), J. Vincent (Hovemere Ltd), and D. Wagner (BU). The ALOMAR RMR lidar project has greatly benefited from the loan of two $1.8 \mathrm{~m}$ mirrors of the European Southern Observatory (Garching, Germany). The project has been funded in part by grants of the Bundesministerium für Forschung und Technolgie (Bonn, Germany), the Kultusministerium Mecklenburg-Vorpommern (Schwerin, Germany), the European Commission (Bruxelles, Belgium), and the Andøya Rocket Range (Andenes, Norway).

Topical Editor D. Murtagh thanks Chiao-Yao She and another referee for their help in evaluating this paper.

\section{References}

Fiedler, J., and G. von Cossart, Automated lidar transmitter for multiparameter investigations within the Arctic atmosphere, IEEE Trans. Geosci. Remote Sensing, 37, 748-755, 1999.

Hauchecorne, A., M.-L. Chanin, and P. Keckhut, Climatology and trends of the middle atmospheric temperature $(33-87 \mathrm{~km})$ as seen by Rayleigh lidar above south of France, J. Geophys. Res., 96, 15 297-15 309, 1991.

Nedeljkovic, D., A. Hauchecorne, and M.-L. Chanin, Rotational Raman lidar to measure the atmospheric temperature from the ground to $30 \mathrm{~km}$, IEEE Trans. Geosci. Remote Sensing, 31, 90$101,1993$.

Rees, D., M. Vyssogorets, N. P. Meredith, E. Griffin and Y. Chaxell, The Doppler wind and temperature system of the ALOMAR lidar, J. Atmos. Terr. Phys., 58, 1827-1842, 1996.

Rees D., U. von Zahn, W. Singer, G. von Cossart, G. Nelke, K. H. Fricke and N. D. Lloyd, The Doppler wind and temperature system of the ALOMAR Lidar, in Proc. 13th ESA Symp. on European Rocket and Balloon Programmes and Related Research, Ed. B. Kaldeich-Schürmann, ESA SP-397, 121-128, 1997.

Rees, D., U. von Zahn, G. von Cossart, K. H. Fricke, W. Eriksen, and J. A. McKay, Daytime lidar measurements of the stratosphere and mesosphere at the ALOMAR observatory, $A d v$. Space Res., 26, 6, 2000.

Vincent, R. A., and I. M. Reid, HF Doppler measurements of mesospheric gravity wave momentum fluxes, J. Atmos. Sci., 40, 1321-1333, 1983.

von Cossart, G., J. Fiedler, and U. von Zahn, Size distributions of NLC particles as determined from 3-colour observations of NLC by ground-based lidar, Geophys. Res. Lett., 26, 15131516, 1999.

von Zahn, U., E. V. Thrane, and R. Skatteboe, The ALOMAR facility: status and outlook, in Proc. 12th ESA Symp. on European Rocket and Balloon Programmes and Related Research, Ed. B. Kaldeich-Schürmann, ESA SP-390, 379-385, 1995.

Young, A. T., Rayleigh scattering, Phys. Today, 35, 42-48, 1982. 
Additional references with science results obtained using the RMR lidar are:

Fiedler, J., G. von Cossart, U. von Zahn, and W. Eriksen, Stratospheric/mesospheric temperature profiles obtained by the ALOMAR RMR lidar over Andøya, in Proc. 14th ESA Symp. on European Rocket and Balloon Programmes and Related Research, Ed. B. Kaldeich-Schürmann, ESA SP-437, 263-268, 1999.

Fierli, F., A. Hauchecorne, D. Nedeljkovic, H. Mehrtens, U. von Zahn, and K. H. Fricke, Relationship between PSC events and temperature measured by ALOMAR RMR lidar at Andøya $\left(69^{\circ} \mathrm{N}, 16^{\circ} \mathrm{E}\right)$, in Atmospheric Ozone: Proc. XVIII Quadrennial Ozone Symp., Ed. R. D. Bojkov and G. Visconti, 503-506, 1998.

Hauchecorne, A., D. Nedeljkovic, M.-L. Chanin, B. Nardi, G. von Cossart, J. Fiedler, U. von Zahn, K. H. Fricke, and V. Nussbaumer, Evolution of the stratospheric temperature and relation with the presence of PSCs as seen by ALOMAR Rayleigh and Raman lidar during SESAME, in Polar Stratospheric Ozone, Air pollution Res Rep. 56, Ed. J. A. Pyle, N. R. P. Harries, and G. T. Amanatidis, 117-121, 1996.

Hoffmann, P., G. von Cossart, and W. Singer, Dynamical influences on PMSE and NLC derived from radar and lidar measurements at ALOMAR, in Proc. 14th ESA Symp. on European Rocket and Balloon Programmes and Related Research, Ed. B. KaldeichSchürmann, ESA SP-437, 305-308, 1999.

Hoppe, U.-P., T. Eriksen, E. V. Thrane, T. A. Blix, J. Fiedler, and F.-J. Lübken, Observations in the polar middle atmosphere by rocket-borne Rayleigh lidar: First results, Earth, Planets. Space, 51, 815-825, 1999.

Nussbaumer, V., K. H. Fricke, M. Langer, W. Singer, and U. von Zahn, First simultaneous and common volume observations of noctilucent clouds and polar mesosphere summer echoes by lidar and radar, J. Geophys. Res., 101, 19 161-19 167, 1996.

von Cossart, G., J. Fiedler, and U. von Zahn, Interannual variability of noctilucent clouds as observed at $69^{\circ} \mathrm{N}$ by ground based lidar, in Proc. 14th ESA Symp. on European Rocket and Balloon Programmes and Related Research, Ed. B. Kaldeich-Schürmann, ESA SP-437, 299-303, 1999.

von Cossart, G., J. Fiedler, U. von Zahn, H. Hansen, and U.-P. Hoppe, Noctilucent clouds: One- and two-color observations, Geophys. Res. Lett., 24, 1635-1638, 1997.

von Zahn, U., Achievements of ALOMAR, in Proc. 13th ESA Symp. on European Rocket and Balloon Programmes and Related Research, Ed. B. Kaldeich-Schürmann, ESA SP-397, 141-159, 1997.

von Zahn, U., and J. Bremer, Simultaneous and common-volume observations of noctilucent clouds and polar mesosphere summer echoes, Geophys. Res. Lett., 26, 1521-1524, 1999.

von Zahn, U., G. von Cossart, J. Fiedler, and D. Rees, Tidal variations of noctilucent clouds measured at $69^{\circ} \mathrm{N}$ latitude by ground based lidar, Geophys. Res. Lett., 25, 1289-1292, 1998.

von Zahn, U., J. Fiedler, B. Naujokat, U. Langematz, and K. Krüger, A note on record-high temperatures at the northern polar stratopause in winter 1997/98, Geophys. Res. Lett., 25, 41694172, 1998. 